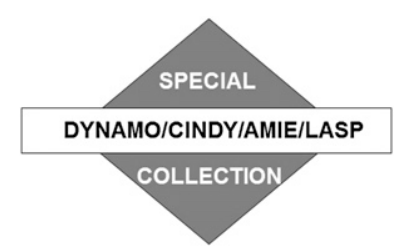

\title{
Surface-Based Microwave Humidity Retrievals over the Equatorial Indian Ocean: Applications and Challenges
}

\author{
JIANHAO ZHANG AND PAQUITA ZUIDEMA \\ University of Miami, Miami, Florida \\ DAVID D. TURNER \\ Global Systems Division, NOAA/Earth System Research Laboratory, Boulder, Colorado \\ MARIA P. CADEDDU \\ Argonne National Laboratory, Argonne, Illinois
}

(Manuscript received 19 October 2017, in final form 26 May 2019)

\begin{abstract}
The interactions between equatorial convection and humidity as a function of height, at a range of time scales, remain an important research frontier. The ability of surface-based microwave radiometry to contribute to such research is assessed using retrievals of the vertical structure of atmospheric humidity above the equatorial Indian Ocean, developed as part of the Dynamics of Madden-Julian Oscillation field campaign. The optimally estimated humidity retrievals are based on radiances at five frequencies spanning $20-30 \mathrm{GHz}$ and are constrained by radiometer-derived water vapor paths that compare well to radiosonde values except in highly convective conditions. The moisture retrievals possess a robust 2 degrees of freedom, allowing the atmosphere to be treated as two independent layers. A mean bias of $1 \mathrm{~g} \mathrm{~kg}^{-1}$ contains a vertical structure that is removed in the assessments. The retrieved moisture profiles are able to capture humidity variability within two layer averages at intraseasonal, synoptic, and daily time scales. The retrieved humidity profiles at hourly scales are qualitatively correct under synoptically suppressed conditions but with an exaggerated vertical bimodality. The retrievals do not match radiosonde profiles within most of the day prior to/after convection. This analysis serves to better delineate applications for radiometers. Radiometers can usefully augment more expensive radiosonde networks for longer-term monitoring given careful cross-instrument calibration. At shorter time scales, a synergism with additional instruments can likely increase the realism of the retrievals.
\end{abstract}

\section{Introduction}

The Madden-Julian oscillation (MJO) is a large-scale circulation that is more strongly defined by variations in humidity than temperature (e.g., Sobel et al. 2001; Zhang 2005). The time scales at which cloud structures interact with the humidity field are important for distinguishing the mechanisms encouraging Madden-Julian oscillation initiation, development, and propagation. One line of argument holds that clouds respond to externally imposed changes, primarily the horizontal advection of moisture (Hohenegger and Stevens 2013; Chikira 2014; Hannah et al. 2016). Another line of argument attributes the large-scale column moistening preceding the active

\footnotetext{
Corresponding author: Jianhao Zhang, jzhang@miami.edu
}

phase of the MJO more directly to the vertical transport of moisture by clouds (Bladé and Hartmann 1993; Benedict and Randall 2007; Powell and Houze 2013; Xu and Rutledge 2016). A radiative feedback by which the vertical and horizontal moisture transport constructively act together has also been postulated (e.g., Ciesielski et al. 2017). This feedback focuses more on the interaction of the largescale circulation with convective variability at smaller scales, such as through shallow-to-deep convective transitions (e.g., Xu and Rutledge 2016) and through the diurnal cycle (Ruppert and Johnson 2015).

Accurate estimates of the moisture field and its variability at a range of time scales are essential for studying convection and its two-way interaction with humidity. The continuing number of studies devoted to understanding tropical moisture-convection-radiation 
interactions (e.g., Holloway et al. 2017; Mapes et al. 2017; Chandra et al. 2018, manuscript submitted to J. Geophys. Res. Atmos., and references therein) argues for more techniques with which to assess the horizontal and vertical distribution of moisture. Radiosondes accurately estimate the atmospheric state, and radiosonde networks have demonstrated their value for understanding and constraining equatorial moisture and heat budgets (Johnson et al. 2015, and references therein). Such networks possess a 3-hourly temporal resolution at best, and the spatial sampling is sparse enough that significant moisture filaments can be missed (Hannah et al. 2016). Satellite measurements of column water vapor path provide improved spatial resolution, but they have more difficulty resolving moisture variations in the lower free troposphere because of contributing surface emission, especially over land.

Another approach, explored within this study, is that of surface-based microwave radiometry. Microwave radiometers have a long history of accurate retrievals of column-integrated water vapor path (WVP) and liquid water path (LWP) in nonprecipitating to lightly precipitating conditions (e.g., Zuidema et al. 2005; Turner et al. 2007), including in tropical environments (Holloway and Neelin 2009; Kuo et al. 2018), and possess the advantages of being autonomous, cloud penetrating, and relatively maintenance-free (Cadeddu et al. 2013). More ambitious studies have also demonstrated some potential for microwave radiometers to retrieve vertically resolved temperature and humidity profiles (Hewison 2007; Löhnert et al. 2007; Blumberg et al. 2015). Löhnert et al. (2009) examined retrievals based on simulated clear-sky conditions from Darwin, Australia, and found their humidity retrieval provided approximately 3 vertical degrees of freedom, with a mean humidity bias of $0.5 \mathrm{~g} \mathrm{~m}^{-3}$. This vertical resolution is far coarser than that available from radiosondes but nevertheless captures the vertical moisture variability that is most important for tropical convective development (Sherwood 1999; Holloway and Neelin 2009), especially because the radiometer is preferentially sensitive to the moisture variations in the lower free troposphere.

Few surface-based microwave radiometry assessments have been made to date of the moisture structure in the tropics. Exceptions include Löhnert et al. (2009) and Raju et al. (2013); the latter is a case study of the water vapor field surrounding a tropical water spout from a scanning microwave radiometer. We extend this research area into the equatorial Indian Ocean and adopt two approaches for evaluating surface-based microwave radiometry humidity profiling. One approach examines the retrieval accuracy itself, whereas the second approach assesses radiometry's ability to capture equatorial humidity variability at a range of time scales. Examined time scales encompass daily resolutions of the MJO 30-50-day intraseasonal time scale, the diurnal cycle during more convectively suppressed conditions, and the more challenging subdaily time scales characteristic of individual convective events. The shorter time scales build on the strength of the radiometer to continually sample every minute.

As part of the Dynamics of the Madden-Julian Oscillation (DYNAMO) campaign (Yoneyama et al. 2013), the University of Miami's 22-30-GHz radiometric microwave radiometer (MWR) was deployed to Gan Island of the Addu Atoll in the Maldives $\left(0.7^{\circ} \mathrm{S}, 73.2^{\circ} \mathrm{E}\right)$, where it was collocated with the NCAR S-band/ Ka-band dual-polarization, dual-wavelength Doppler (S-PolKa) radar (Sahoo et al. 2015). The data for this study were collected from 18 October 2011 to 14 January 2012. The radiometer's frequency range is arguably the most commonly applied in deployed radiometers worldwide, but it excludes the temperature-sensitive oxygen absorption band at $60 \mathrm{GHz}$. Radiosonde information is integral to both the retrieval and its assessment. These are provided by the Atmospheric Radiation Measurement (ARM) MJO Investigation Experiment (AMIE; Long et al. 2011), which brought the ARM Mobile Facility 2 (AMF2; Miller et al. 2016) to a location that is approximately $8.5 \mathrm{~km}$ southeast of the radiometer.

A detailed description of the instruments and the radiative transfer model is provided in section 2 , augmented by the appendix. The retrieval algorithms are introduced in section 3. Section 4 contains several quantitative evaluations of the accuracy of the profile retrievals, including a bias analysis and sensitivity tests. In section 5, the radiometer-derived moisture structure and its variability at different time scales (diurnal, convective scale, daily mean, and intraseasonal) are evaluated by comparing with radiosonde-derived values. Section 6 provides a conclusive summary of the lessons learned from this study and an outlook for the potential roles of MWRs in future field campaigns.

\section{Instrument and model descriptions}

\section{a. Radiosondes}

The AMF2 launched Vaisala, Inc., RS-92 radiosondes 8 times per day, totaling 763 successful launches from 18 October 2011 to 14 January 2012. The radiosonde measurements are corrected for a daytime dry bias attributed to solar heating (Wang et al. 2013; Ciesielski et al. 2014). As expected, the radiosonde temperature profiles varied little throughout the campaign (Fig. 1a), with a standard deviation of about $0.5^{\circ} \mathrm{C}$ among the 763 temperature profiles and a variation of $<0.5^{\circ} \mathrm{C}$ between 

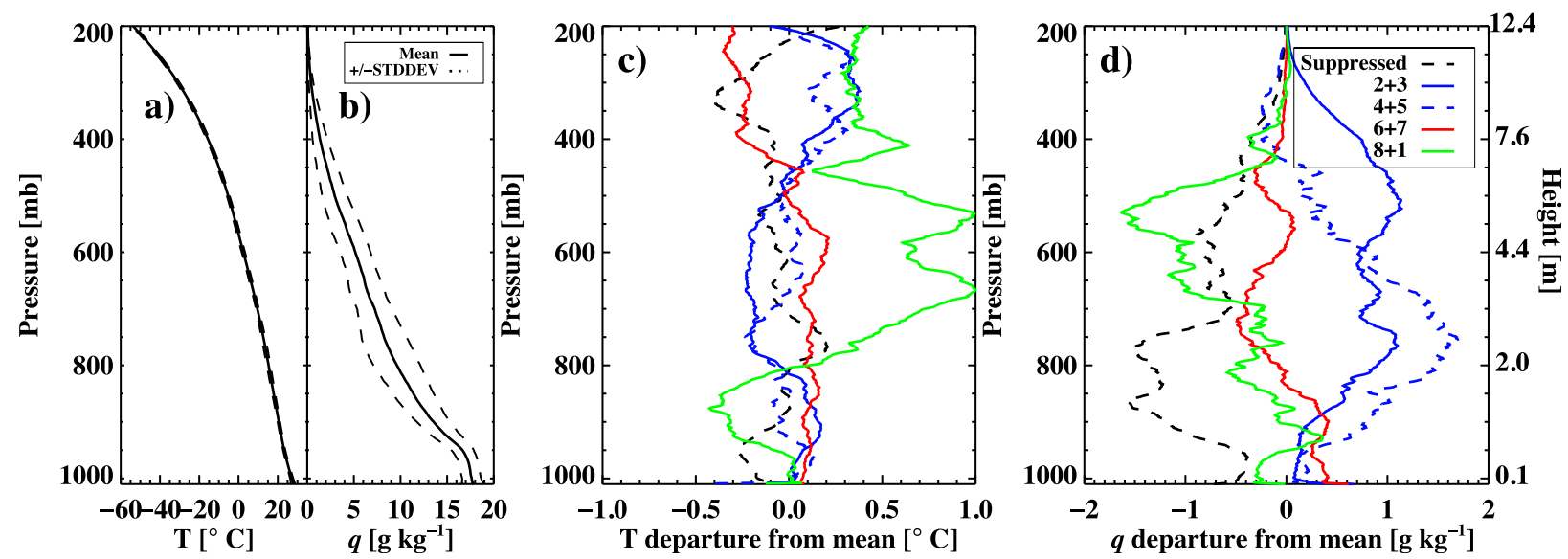

FIG. 1. Mean profiles of (a) temperature and (b) water vapor mixing ratio $q$ with 1 standard deviation (dashed curves) calculated from 763 radiosondes between 19 Oct 2011 and 14 Jan 2012. Also shown is the departure from the mean values of (c) temperature and (d) $q$ as a function of the MJO phases (as indicated in the color key).

the mean temperature profiles corresponding to different conditions (phases) of the MJO, discussed further in section 5a (Fig. 1c). These 763 temperature and humidity profiles provide the a priori information for the humidity retrieval. Following Löhnert et al. (2004), the 763 radiosondes profiles are first interpolated onto a 53-level semiexponential height grid, with a vertical grid spacing of $10 \mathrm{~m}$ at the surface, decreasing with height to $500 \mathrm{~m}$ at $14 \mathrm{~km}$. The 53 levels establish the vertical grid for the humidity retrieval.

\section{b. Radiometer}

The model PR203090 Radiometrics scanning radiometer possesses 21 channels between 22 and $30 \mathrm{GHz}$, sampling along different positions on the pressurebroadened 22.235- $\mathrm{GHz} \mathrm{H}_{2} \mathrm{O}$ absorption line. The utilized zenith-pointing scans are embedded within a scanning pattern set to match that of a collocated S-PolKa radar (Sahoo et al. 2015), and as such had irregular time stamps, but with data available every minute. The radiometer maintains its calibration through an automated routine, whereby observations are gathered at a range of airmass opacities by varying the elevation angle. The range of sampled angles also tests for the horizontal homogeneity of the atmosphere, thereby selecting for clear skies. These measurements ultimately establish the accuracy of the temperature of an internal noise diode, with the instrument noise contributing an estimated root-meansquare error or uncertainty in the brightness temperature of $0.3 \mathrm{~K}$ (Turner et al. 2007).

The continual scanning pattern reaches near-surface elevations that discourage water accumulation upon the radome. Further efforts are made to identify precipitation conditions, as drop sizes exceeding $200 \mu \mathrm{m}$ begin to violate the Rayleigh absorption and scattering assumptions assumed within the humidity retrieval (Cadeddu et al. 2017). The S-PolKa site lacked direct rain measurements, and the S-PolKa radar did not include a zenithpointing stare. Instead, the radiometer measurements themselves are used to identify rain contamination. Cases in which the retrieved LWP $>1500 \mathrm{~g} \mathrm{~m}^{-2}$ are not included in the 30-min averages input into the humidity retrieval, whereas 30-min LWP averages of $>500 \mathrm{~g} \mathrm{~m}^{-2}$ are also subsequently excluded from further analysis. This metric indicated slightly more precipitation than the rain gauge at the ARM site, suggesting that it is a conservative choice. As shown later, most of the LWPs in the final humidity retrieval dataset were less than $100 \mathrm{~g} \mathrm{~m}^{-2}$ - values for which large drop sizes are uncommon (Zuidema et al. 2005).

\section{c. Radiative transfer model}

All retrievals rely on iterations of radiances computed using the Monochromatic Radiative Transfer Model (MonoRTM), version 5.0, developed by the Atmospheric and Environmental Research Co. MonoRTM includes line-coupling effects (Hoke et al. 1989) and uses "MT_CKD 2.5.2" for the water vapor continuum and the Humliček-Voigt line shape (Humliček 1982). Halfwidths of the two main water vapor lines are documented in Payne et al. (2008). Further details regarding MonoRTM's inputs, outputs, and model parameters can be found in Clough et al. (2005).

\section{Method}

Humidity profiling using microwave radiometry is inherently challenging because the retrieval is underconstrained. Bayesian optimal estimation approaches incorporate a priori information to help to constrain the 


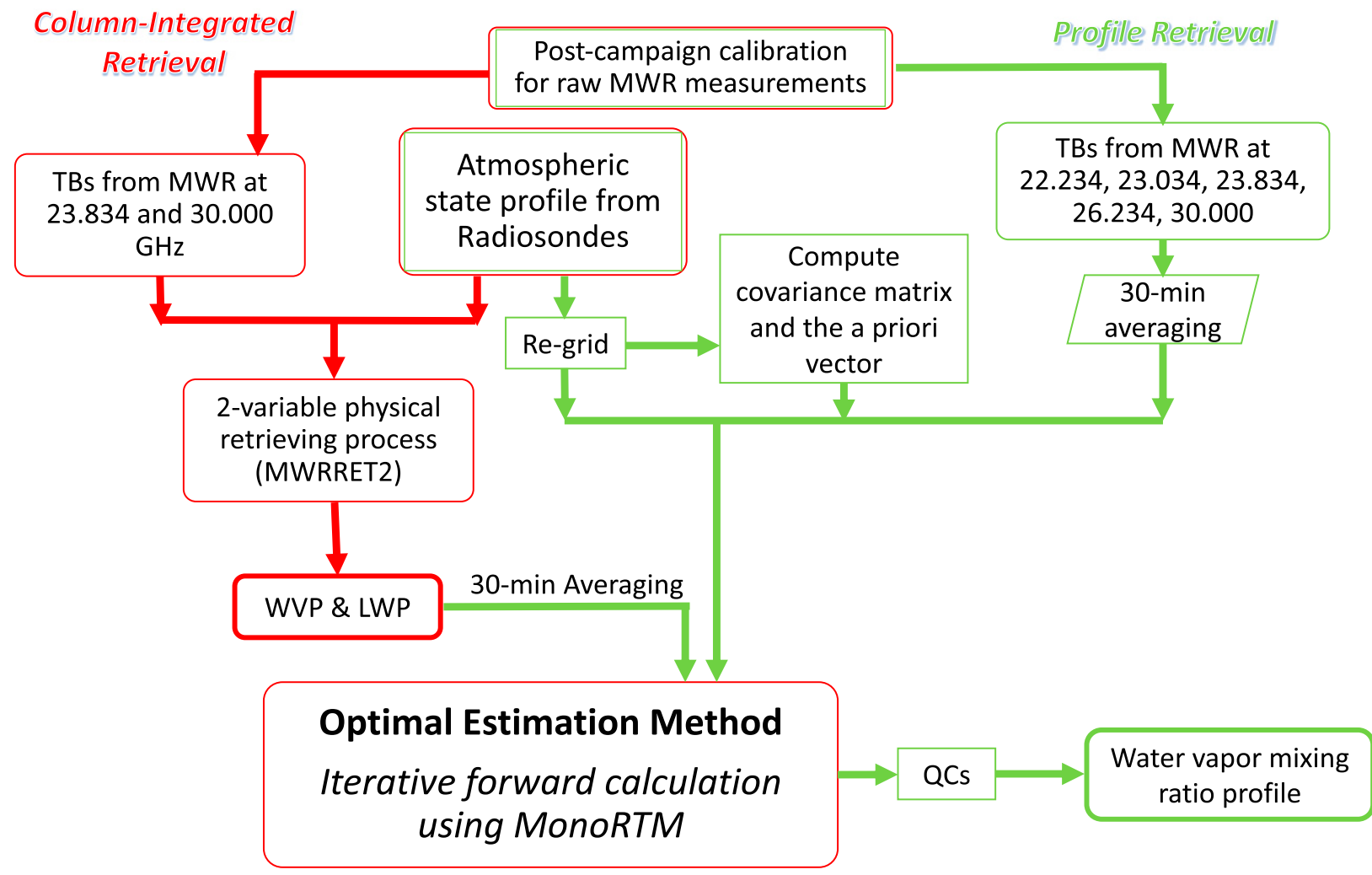

FIG. 2. A flowchart indicating the column-integrated retrieval (red frames and arrows) and profile retrieval (green frames and arrows). The postcampaign calibration and quality controls are defined in sections $3 \mathrm{a}$ and $3 \mathrm{~b}$, respectively.

retrieval solution, and they produce an error estimate as part of their retrieval (Rodgers 2000). We apply the same Bayesian optimal estimation approach as in Löhnert et al. (2004, 2009) and Blumberg et al. (2015). The a priori information is constructed from the deployment-mean radiosonde-derived humidity and temperature profiles. This approach reflects what can typically be done prior to a field deployment. The column-integrated water vapor estimates are constructed first and compared with those derived from radiosondes. This helped uncover a pointing error that is corrected prior to the humidity profile retrieval. The column-integrated moisture values are integrated as a constraint on the humidity profile retrieval. This is not typically done, but the constraint improves the subsequent profile retrieval by reducing compensating variability at different altitudes and improves the representation of the boundary layer moisture in particular. A flowchart (Fig. 2) facilitates understanding of the approach described further below.

\section{a. Column-integrated WVP and LWP retrievals}

The column-integrated WVP and LWP retrievals are more robust than the retrieved humidity profiles because the two column-integrated measures can be fully constrained using only two brightness temperatures, at frequencies of 23.834 and $30.0 \mathrm{GHz}$. These retrievals are performed at approximately 1-min resolution using an algorithm that is also the basis of the standard ARM operational retrieval ("MWRRET2"; Turner et al. 2007). The effective radiating temperature of the low clouds, to which the liquid absorption coefficient is sensitive, is established through cloud boundaries set at 800 and $1300 \mathrm{~m}$. The cloud base corresponds to the lifting condensation level, and clouds thicker than $500 \mathrm{~m}$ are susceptible to precipitation and more likely to be excluded from the retrievals. Changes of less than $100 \mathrm{~m}$ in either the cloud-base height or cloud thickness will impact the retrieved LWP, but the impact on the retrieved thermodynamic profile is smaller than the retrieval uncertainty.

Initial column-integrated moisture retrievals revealed a moist bias of $0.2 \mathrm{~cm}$ when compared with values calculated from the radiosondes. A scrutiny of the accelerometer data from the level-0 files revealed an offset between the actual and programmed viewing angles of approximately $11^{\circ}$, reflecting a slanting of the radiometer's base after its deployment. The offset is accounted for in the zenith measurements by a recalibration to a viewing 


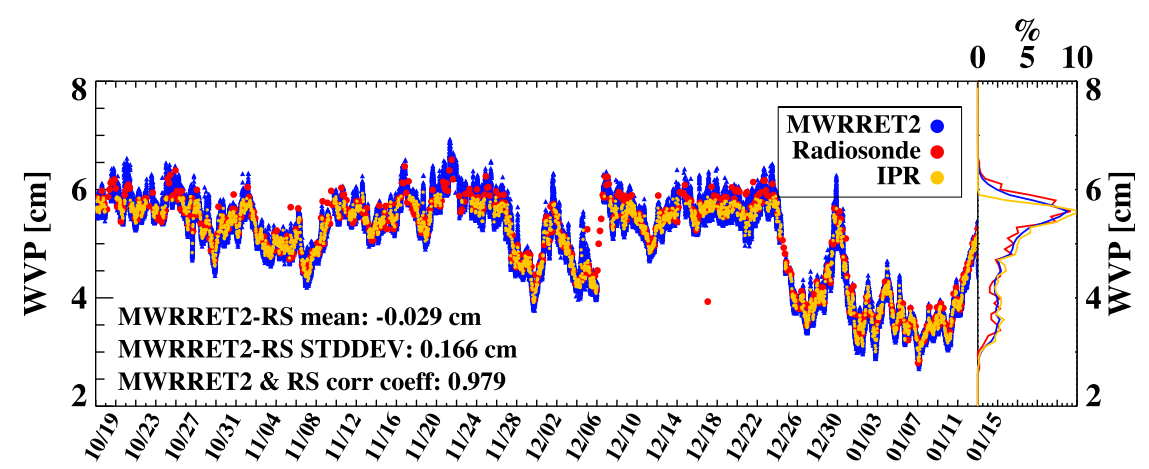

FIG. 3. Time series and frequency distribution of the column WVP derived by MWRRET2 (blue), as an integration of the profile retrievals (label IPR; yellow), and the radiosondes (label RS; red).

angle of $79^{\circ}$, referred as "post-campaign calibration" in the retrieval flowchart (Fig. 2). The subsequent stability of the radiometer over the course of the campaign is examined through comparing the clear-sky observed brightness temperatures with those forward calculated from the radiosondes (e.g., Löhnert and Maier 2012). A time series of this difference indicates that the radiometer is otherwise stable (not shown).

The calibration also accounts for a temperature dependence brought by daytime solar heating of the radiometer. This recalibration produced WVPs that match radiosonde values exceedingly well, with a mean difference of $0.029 \mathrm{~cm}$, standard deviation of the differences of $0.166 \mathrm{~cm}$, and correlation coefficient of 0.979 (Fig. 3, blue dots and red dots). A frequency distribution of the water vapor path retrievals reveals a distinct mode corresponding to a plateau of $5.6 \mathrm{~cm}$, with an overall mean of $5.02 \mathrm{~cm}$ and a standard deviation of $0.81 \mathrm{~cm}$. The main difference from the radiosondes occurs at values of $>6 \mathrm{~cm}$, where the screening for precipitation removes the most moist profiles-a sampling bias that is common to radiometer applications (Kuo et al. 2018). Liquid water paths are also retrieved, and they are subsequently used to indicate the likelihood of rain.

\section{b. Vertically resolved moisture retrievals}

The more-complex humidity profile retrievals rely on the 22.234-, 23.034-, 23.834-, 26.234-, and 30.0-GHz brightness temperatures. The retrieval vectors, composed of the same 53 levels as the semi-exponentially gridded radiosonde profiles, exceed the five elements of the input vector, posing an inherently ill-posed retrieval. An ill-posed inverse problem disallows a unique solution, and small errors in the observation can lead to a different retrieved humidity profile. A scaling of each iterated humidity profile by the previously retrieved water vapor path serves as one constraint. Further constraints rely on the radiosondes, which provide the a priori information expected by the retrieval. The diagonal elements of the a priori $\mathbf{S}_{a}$ covariance matrix contain the variances of the radiosonde water vapor mixing ratio at each altitude, and the off-diagonal elements contain the covariances between different vertical levels of the radiosonde humidity profile. The campaign-mean profile of water vapor mixing ratio is the a priori state vector $\mathbf{X}_{a}$ and the first-guess input to the profile retrieval $\mathbf{X}_{1}$. The campaign-mean profiles are chosen for this retrieval design, as opposed to a near-in-time earlier profile, to emulate predeployment conditions for which only historical datasets or data from previous field campaigns are available. The campaign-mean temperature profile is assumed to be constant within the retrieval—an assumption that we also test. The input brightness temperature measurements are initially averaged to 30-min resolution, setting the time resolution of the subsequent humidity retrievals. Details of the optimal estimation method follow Rodgers (2000) and are provided in the appendix.

Quality controls include testing for convergence (see the appendix), excluding input LWPs exceeding $500 \mathrm{~g} \mathrm{~m}^{-2}$, and excluding retrievals with a root-meansquare of the fit that is greater than $2 \mathrm{~K}$. The chosen LWP threshold is not sensitive to the exact value: $93 \%$ of the LWPs associated with the final humidity retrieval dataset are $<100 \mathrm{~g} \mathrm{~m}^{-2}$, with an uncertainty of approximately $15 \mathrm{~g} \mathrm{~m}^{-2}$ from instrument noise, far below the LWP threshold of $500 \mathrm{~g} \mathrm{~m}^{-2}$ (Fig. 4). $75 \%$ of the profile retrievals passed all of the quality controls, and only these are shown in subsequent analysis and applications.

A further advantage of optimal estimation is that the retrieval uncertainties can be directly computed as the mean quadratic error estimate from the diagonal elements of the covariance matrix for the optimal solution $\mathbf{S}_{\mathrm{op}}$. Similarly, the number of independent vertical levels 


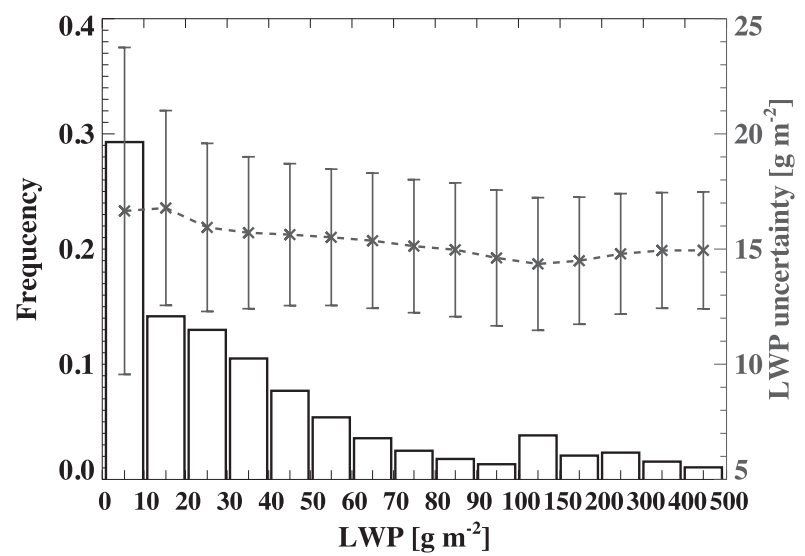

FIG. 4. Frequency histogram of the retrieved LWPs, along with the mean uncertainty (dashed line with times signs) and standard deviation (error bars).

is also known directly from the degrees of freedom. The retrievals possess 2.2 independent degrees of freedom (see Fig. A1b and the appendix for details), which is less than the almost 3 that is reported in Löhnert et al. (2009) over Darwin. One cause may be the use of actual versus simulated observations, but another explanation may be that the equatorial atmosphere is more vertically coherent (i.e., possesses a higher vertical autocorrelation) than that of the monsoonal, coastal environment of north Australia.

Time series of the radiometer and radiosonde moisture profile retrieval anomalies from their respective means are shown at 3-h resolution in Fig. 5. Similarities are apparent between the retrieved and radiosonde profiles. Moisture variation patterns at 3-5-day time scales and longer are captured well. The most noticeable difference between the two panels is an overstated diurnal cycle in January 2012, the most convectively suppressed time period of the campaign, within the radiometer retrievals.

The retrieved water vapor mixing ratios $q(z, t)$ are shown divided by the time-averaged retrieval profile $[q(z, t) \overline{q(z)}]$ in Fig. 6 , sorted by the retrieved columnintegrated water vapor path, for both the radiometer retrievals and radiosonde-derived values. This type of representation indicates when a vertical level is drier or more moist than the average. Several well-known features are evident, such as a moistening beginning at the lower altitudes as total-column moisture increases. Interestingly, the boundary layer is more moist at water vapor paths between 4 and $4.5 \mathrm{~cm}$ than at WVPs exceeding $5 \mathrm{~cm}$, evident in both the retrievals and radiosonde datasets. We speculate that a column water vapor of $4.8-5.0 \mathrm{~cm}$ may be necessary to support convection that is deep enough to generate downdrafts capable of bringing down drier air. Also apparent, by comparing the spread of the 5-6-cm humidity profiles between radiosondes and retrievals, is that most of the nonconverged/ excluded profiles correspond to the more-saturated atmospheres that are more likely to be precipitating.

\section{Retrieval assessment}

Although there is no bias to the integrated water vapor values by construction, a vertically varying bias is apparent in the retrieved humidity profiles (Fig. 7; black solid curve). The retrievals are too dry below $1.5 \mathrm{~km}$ by up to $1 \mathrm{~g} \mathrm{~kg}^{-1}$, too moist between 1.5 and $5 \mathrm{~km}$ by up to $1.5 \mathrm{~g} \mathrm{~kg}^{-1}$, and too dry above $5 \mathrm{~km}$. These values correspond to maximum differences in the absolute humidity of $-1.3 \mathrm{~g} \mathrm{~m}^{-3}$ near the surface and $1.6 \mathrm{~g} \mathrm{~m}^{-3}$ near $3 \mathrm{~km}$. The mean bias is relatively smaller when the WVP is less than $5 \mathrm{~cm}$, and even more for WVPs of less than $4 \mathrm{~cm}$, whereas the largest biases occur for WVPs of greater than $5 \mathrm{~cm}$ (gray curves in Fig. 7). The vertical structure does not vary with WVP, and the largest root-meansquare errors occur between 5 and $7 \mathrm{~km}$ (Fig. 7; dashed black curve). Although the biases only slightly exceed those reported elsewhere (e.g., Raju et al. 2013), the systematic behavior with altitude invites a search for a cause.

Several tests were done to attribute and mitigate, if possible, the cause for the bias vertical structure. One was to examine the sensitivity of the humidity retrievals to the temperature profile through varying it by \pm 1 standard deviation (Fig. 8a). Humidity retrievals based on the warmer temperature profile are more moist below $2 \mathrm{~km}$ than those based on the drier profile and are drier between 3 and $6 \mathrm{~km}$. This is consistent with a downward displacement of the weighting function. A more physically realistic experiment would examine the sensitivity to temperature variations that realistically covary with moisture (through associated changes in latent heat), but the experiment here is enough to indicate that the humidity retrieval is not sensitive enough to the temperature deviation to explain the overall humidity bias. The bimodal vertical structure of the temperature bias is also at odds with the trimodal structure of the humidity bias.

Another test examined the retrieval sensitivity to a systematic bias in the LWP inputs, from, for example, an incorrect gaseous absorption model (e.g., Zuidema et al. 2005). LWPs are perturbed by $\pm 10 \%$ in two sets of retrievals, yielding a mean difference in water vapor mixing ratio of approximately $0.2 \mathrm{~g} \mathrm{~kg}^{-1}$ (Fig. 8b). This is only $\sim 20 \%$ of the humidity biases noted in Fig. 7 -also not enough to explain the bias. The concern that samples possessing WVPs of greater than $5 \mathrm{~cm}$ could contain precipitating clouds is evaluated using only those cases with 
August 2018

Z HANG ET AL.

1771
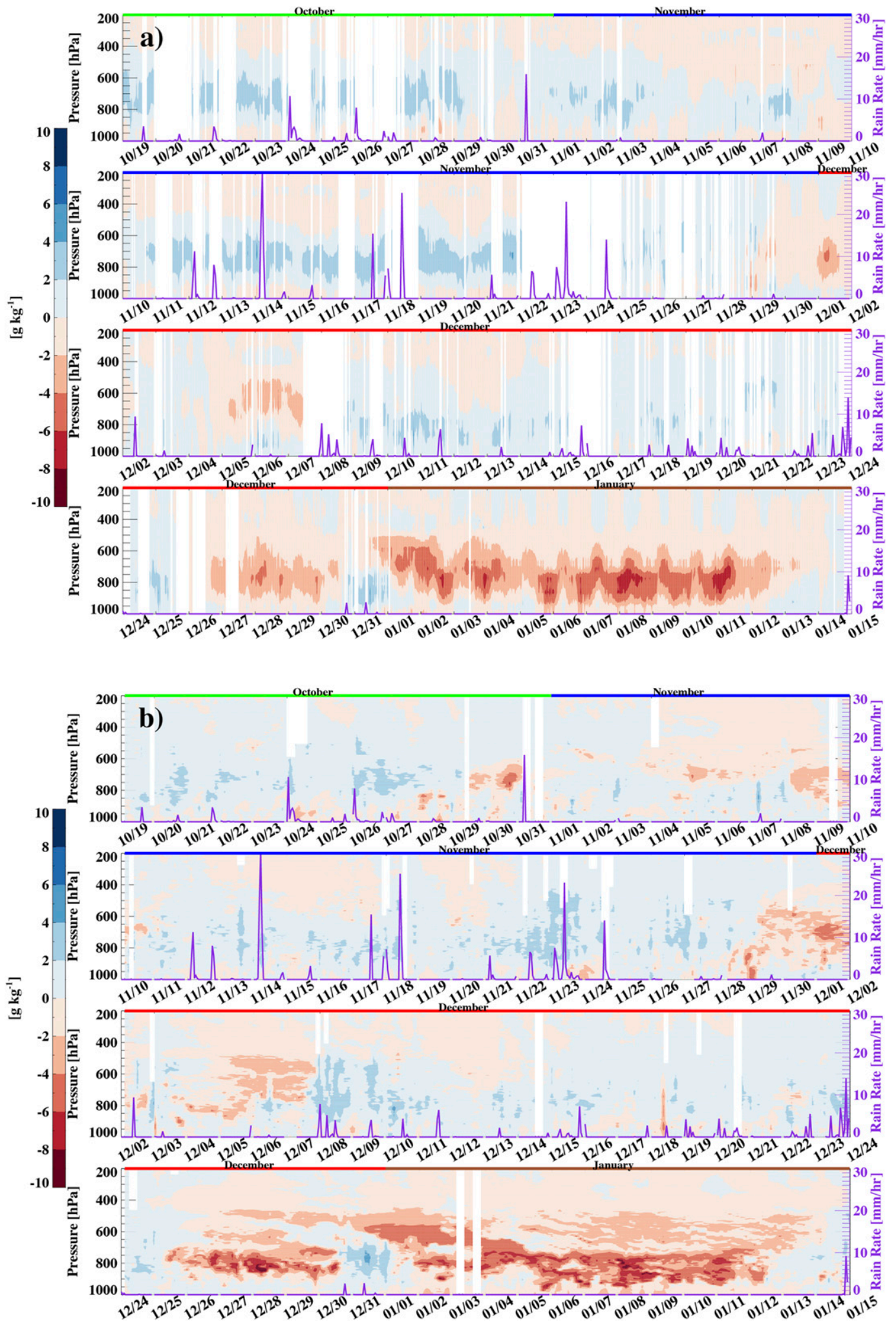

FIG. 5. Time series of $q$-profile anomalies from the mean from (a) the radiometer and (b) radiosondes, at 30-min site is indicated in purple.

Unauthenticated | Downloaded 04/26/23 01:55 PM UTC 

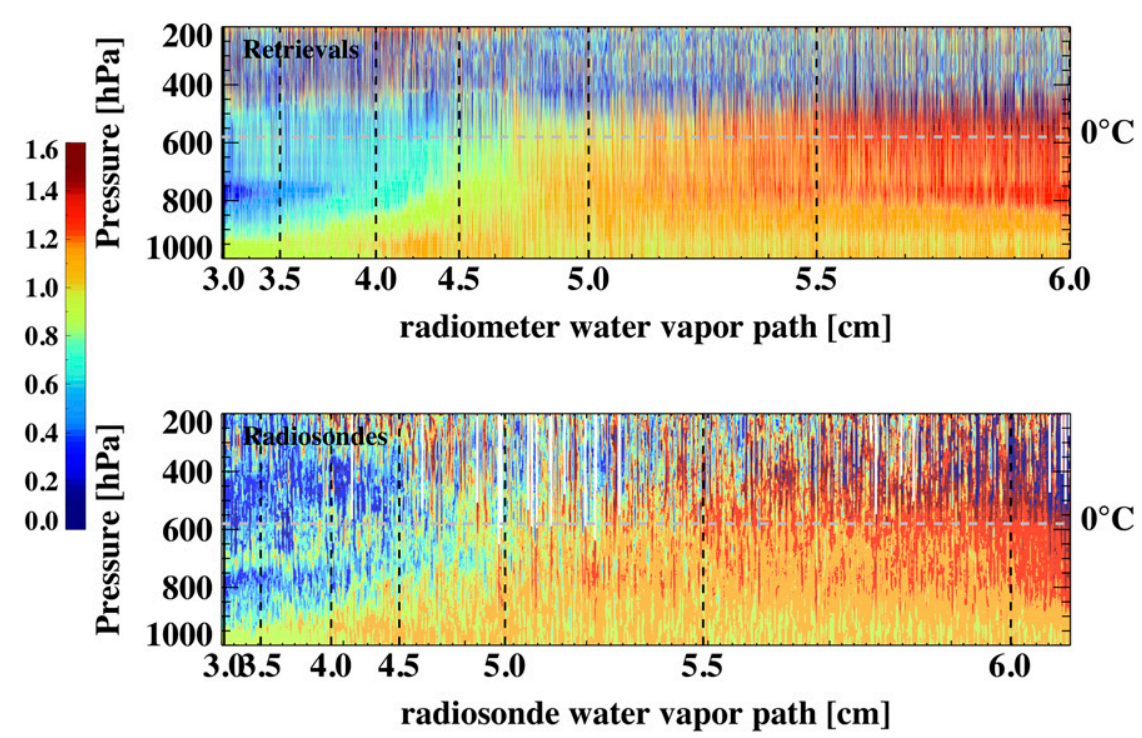

FIG. 6. Profiles of (top) radiometer-retrieved and (bottom) radiosonde water vapor mixing ratio $q(z, t)$ normalized by the time-averaged value at each vertical level $[q(z, t) / q(z)]$, sorted by the retrieved WVP. The $0^{\circ} \mathrm{C}$ level is indicated with a horizontal gray dashed line.

LWPs below $1 \mathrm{~g} \mathrm{~m}^{-2}$. These are not less biased. Random LWP errors introduced by instrument noise will not yield a systematic impact on humidity profile retrievals.

Another attribution effort examines the water vapor continuum representation by strengthening the selfbroadened component by $8 \%$ and weakening the foreign-broadened component by $3.4 \%$, based on prior experimentation (Turner et al. 2009). These modifications did little to affect the mean bias. No further spectroscopic experiments are conducted because of the limits of the short dataset. Experiments with different vertical grid spacings also do not reveal any sensitivity to the vertical grid spacing (see the detailed discussion in the appendix).

A more illuminating experiment selected carefully for a subset of clear-sky radiosondes by using the ARM zenith-pointing $35-\mathrm{GHz}$ cloud radar to screen for cloud. Forward-calculated brightness temperatures based on the selected 50 clear-sky radiosondes contain a slight slope offset when compared with the radiometer brightness temperatures in four of the five channels (Fig. 9). After the slope offset is removed from the observations using a simple linear regression, the mean bias persists but is reversed in sign (too dry in the low troposphere and too moist in the upper troposphere). Given that the change in the slope offset is small, this most clearly indicates the importance of calibration and the calibration dataset, as the more restricted clear-sky radiosonde evaluation dataset applies to a drier environment than is typical. For this reason, the original radiometer brightness temperatures were kept.

\section{Humidity profile retrieval applications as a function of time scale}

A question remains as to why the vertical structure of the bias persists, although the experimentation confirms the importance of calibration. For the assessment of the scientific applications of the radiometer retrievals, the

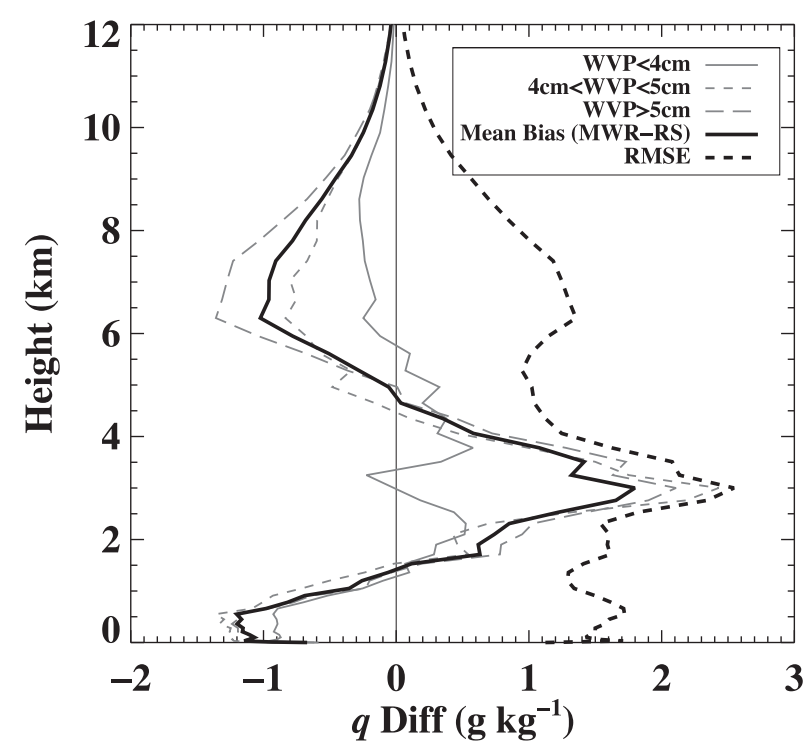

FIG. 7. Mean bias (solid black) and RMSE (dashed black) of retrieved $q$ profiles from the mean of the 763 radiosondes. Gray curves indicate mean bias profiles as a function of three WVP ranges (long dashed line for WVP $>5 \mathrm{~cm}$, dashed line for WVP between 4 and $5 \mathrm{~cm}$, and solid line for $\mathrm{WVP}<4 \mathrm{~cm}$ ). 

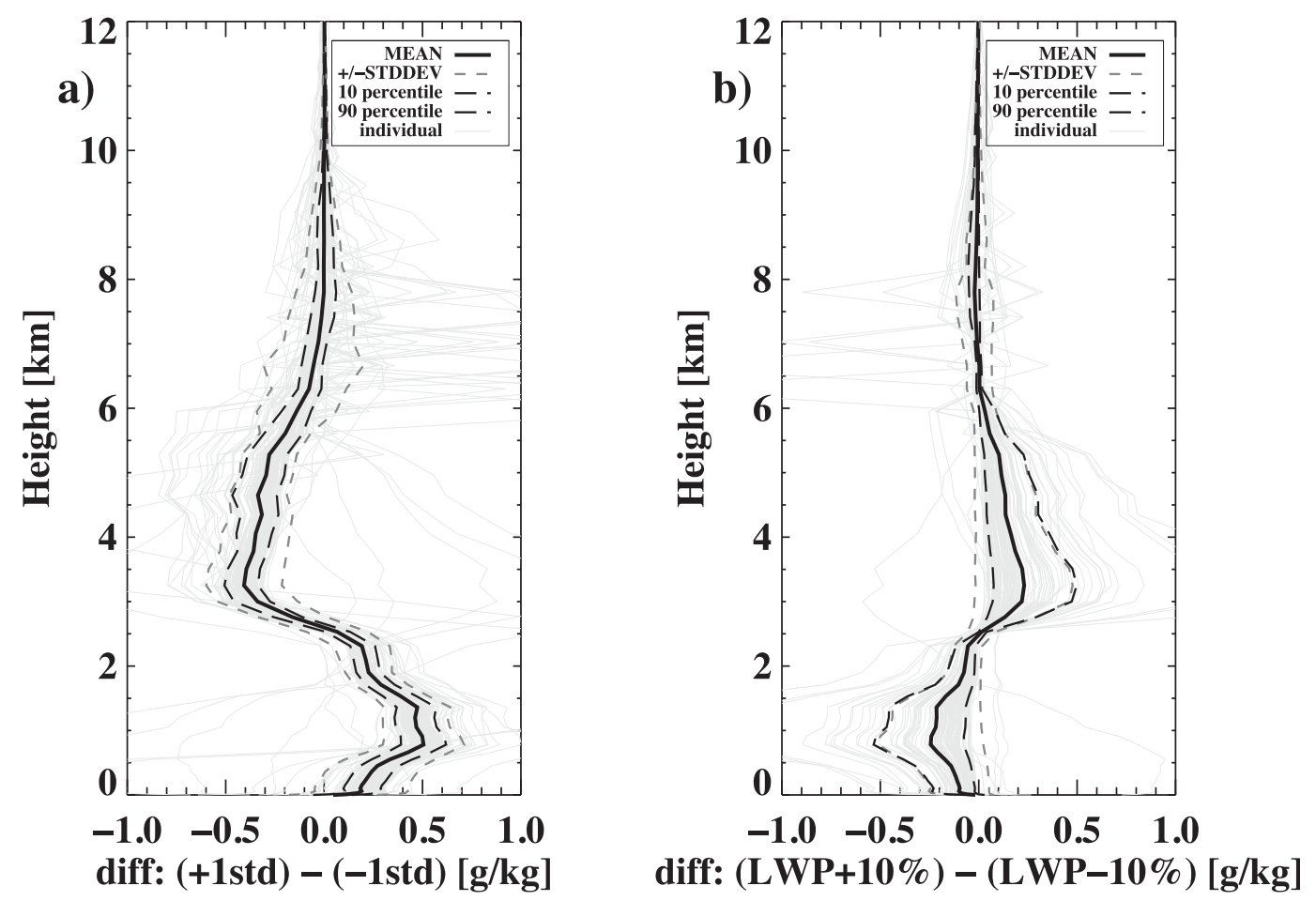

FIG. 8. (a) Differences between mean humidity profile retrievals relying on +1 and -1 standard deviation from the campaign-mean temperature profile, and (b) differences between mean humidity profile retrievals relying on input LWPs perturbed by $+10 \%$ and $-10 \%$. In each case, in addition to the mean result and \pm 1 standard deviation of the results, the 10th-percentile, 90th-percentile, and individual profiles are also shown.

mean vertical structure of the bias (Fig. 7; solid black line) is removed from each retrieved profile. The subsequent assessments evaluate the moisture structure at four time scales: that of the intraseasonally varying MJO, daily moisture changes, as hourly composites centered on strong rain events, and as a diurnal-cycle composite during a suppressed (but still convective) phase of MJO.

\section{a. Intraseasonal moisture variability}

Time series of two separate layer-averaged moisture fields are shown, one spanning $1000-700 \mathrm{hPa}$ and the other $700-400 \mathrm{hPa}$, chosen in light of the approximately 2 available independent degrees of freedom for signal (Fig. 10). These layers correspond approximately to the two height maxima in the averaging kernels (Fig. A1c in the appendix). The two separate layer-integrated moisture retrievals capture the intraseasonal moisture variability well, with their moisture changes often being correlated (consistent with the radiosondes) but not always. For example, from 8 to 9 November, the midtroposphere is moistening while the lower troposphere is drying. In contrast, from 30 to 31 December, the midtroposphere is drying while the lower troposphere was moistening, highlighting that humidity variations can be independently retrieved from the two layers.
The retrievals also capture the mean conditions associated with an external definition of the MJO phase. The MJO phases indicate where convection is active within the global equatorial belt. They are defined by an index that is based on the near-equatorially averaged 850- and 200-hPa zonal winds and satellite-observed outgoing longwave radiation data (Wheeler and Hendon 2004). At Gan Island, phases 1-3 correspond to more organized convection, and phases 4-8 correspond to more suppressed, isolated convection (Gottschalck et al. 2013). An extremely low index value is considered fully suppressed ("S"). Gan Island experienced three MJO events during DYNAMO (Yoneyama et al. 2013); the phases are indicated at the top of Fig. 10. The retrievals are shown as equivalent potential temperatures $\theta_{e}$, a commonly used measure of the moist energy available to tropical convection that is a function of both moisture and temperature. Average profiles of $\theta_{e}$ agree well between the retrievals and radiosondes (Fig. 11). The relative agreement is poorest in the boundary layer, where the "suppressed" retrieved profile indicates a high $\theta_{e}$ and the radiosondes do not. This is in part a reflection of the use of a constanttemperature vertical profile, as moister profiles tend to be cooler, introducing a compensation to $\theta_{e}$ that is not captured within the retrievals. Overall, though, it is clear that 

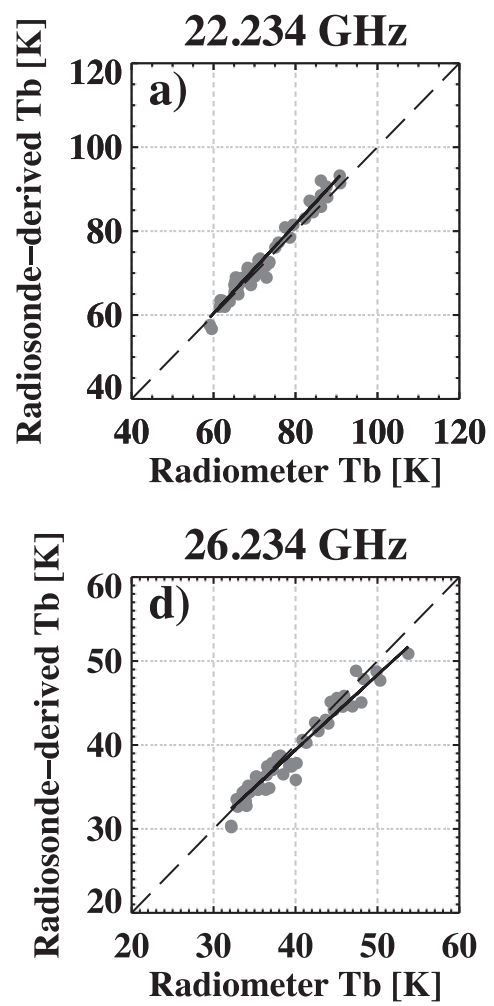
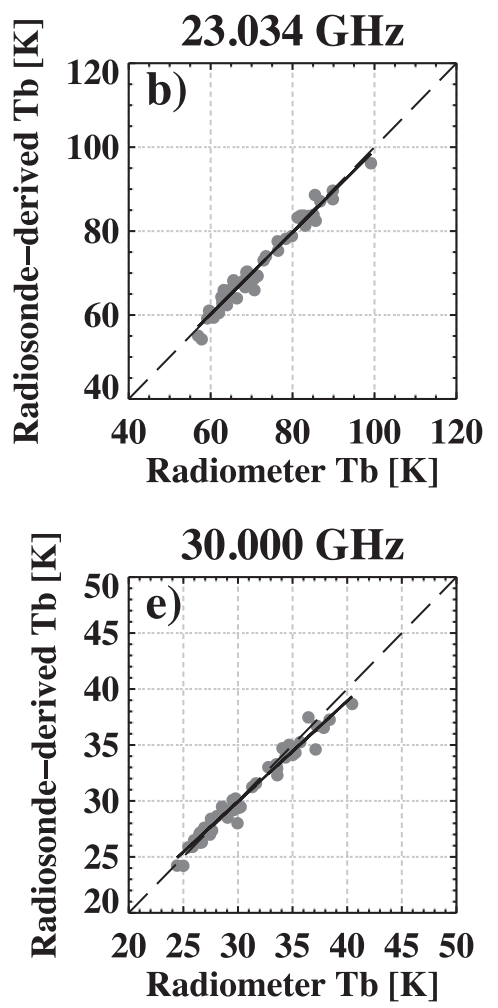

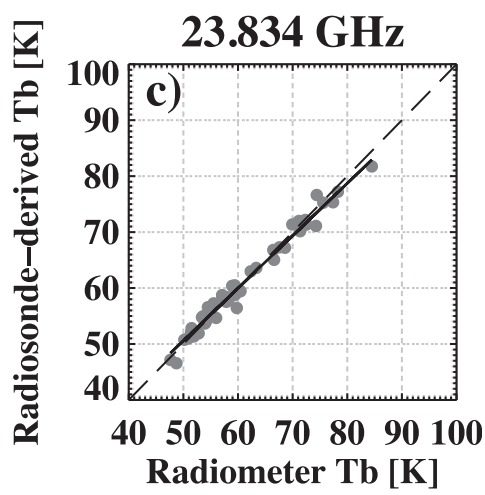

FIG. 9. Brightness temperatures calculated from 50 clear-sky soundings selected from a stringent comparison with cloud radar measurements vs radiometer measurements at (a)-(e) five different frequencies. The linear regression line (solid) and $X=Y$ line (long dashed) are both indicated. a network of microwave radiometers could serve well to monitor large-scale changes in such coarsely resolved vertical layers.

\section{b. Daily moisture variability}

Day-to-day changes in $q(z)$ can reflect either horizontal or vertical moisture advection, and the monitoring of these changes is beneficial for understanding how moisture interacts with convection at daily time scales (e.g., Xu and Rutledge 2016). The daily changes in water vapor mixing ratio are calculated from a straightforward subtraction of daily mean moisture profiles from those of the previous day, in both the retrievals and radiosondes (Fig. 12). Filled color contours show increases (blue) and decreases (red) in moisture from both the retrievals and radiosonde measurements. The retrieved daily changes in water vapor agree well with those derived from radiosondes, both in sign and magnitude. This is also revealed in the correlation analysis of Fig. 12c, with the occasional weak correlations occurring on days when the humidity variability was weak overall, such as from 23 to 25 October and 17 to 19 December. Retrieved changes to the humidity profile are also realistic during time periods when these are vertically incoherent, such as from 8 to 9 November and 30 to 31 December (correlations of 0.87 and 0.86 , respectively, between the retrieved and radiosonde vertical structures).
The boundary layer (approximately 1000-900 hPa) moisture varies less than that within the free troposphere, and the retrievals capture this distinction well. The lack of intrinsic moisture variability also helps to explain why the retrievals near the surface and above $200 \mathrm{hPa}$ do not correlate as well with the radiosonde-derived changes as in the midtroposphere. A recurring pattern of moisture fluctuation at a period of about 3-5 days (i.e., a drying event followed by a moistening event) is evident in both datasets in November and December as noted by Zuluaga and Houze (2013), although these did not reach statistical significance within a power-spectrum analysis. Overall, this comparison supports the application of microwave radiometers toward resolving moisture changes at daily time scales, at a coarse vertical resolution.

\section{c. Moisture evolution relative to convection}

A more ambitious goal is to assess if the radiometer retrievals can capture the evolution of moisture relative to deep convective events. In a typical evolution (e.g., Mapes et al. 2006; Holloway and Neelin 2009), moisture accumulates first within the boundary layer, which deepens and reaches into the free troposphere approximately a half-day before the maximum rainfall. After the rainfall, the boundary layer weakly dries, with the drier boundary layer deepening gradually over the subsequent day. This evolution is also documented for 

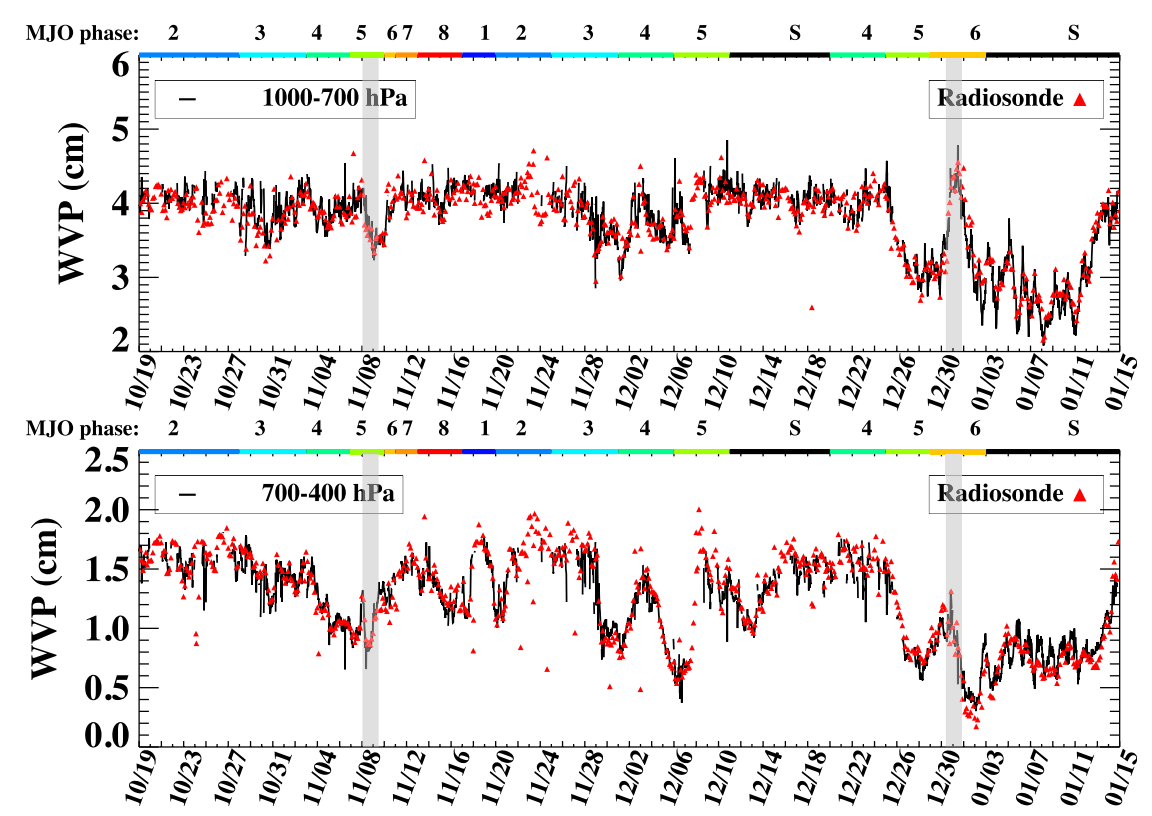

FIG. 10. Layer-integrated WVP time series of the radiometer retrievals (black) and radiosonde-derived values (red) for the (top) 1000-700-hPa and (bottom) 700-400-hPa layers. MJO phases are indicated above each panel. Gray-shaded areas indicate two time periods during which the layer-averaged moistures differ. Retrieved values are at 30-min resolution.

the 11 events providing the most rain accumulation at Gan Island using radiosondes and ERA-Interim data (Zuluaga and Houze 2013). The evolution reflects a summation of subtle entrainment, mass-flux, and cold-pool processes (e.g., Tompkins and Semie 2017; Zuidema et al. 2017; Schiro and Neelin 2018) for which vertically resolved moisture information available at smaller time scales than those of radiosondes is potentially useful.
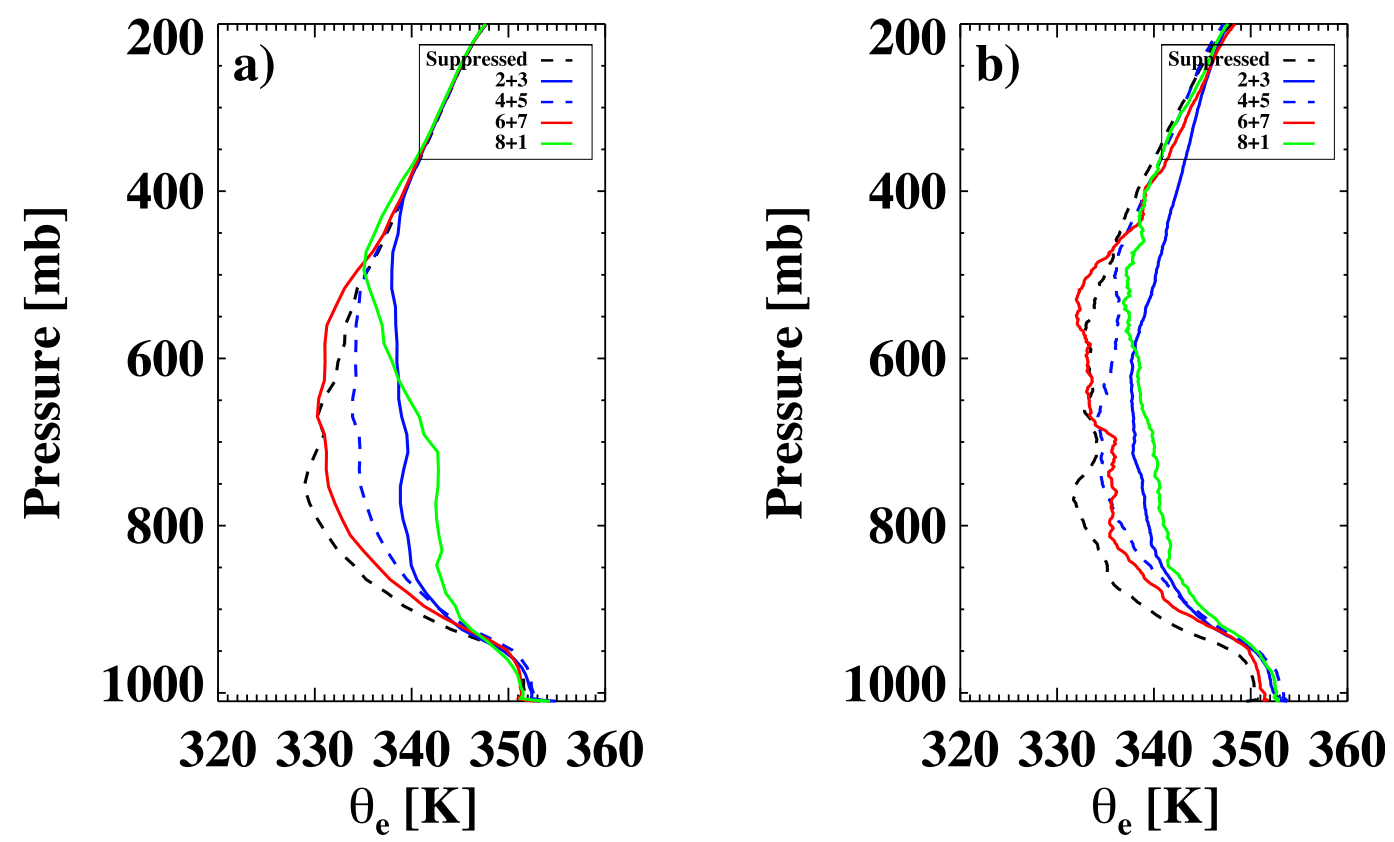

FIG. 11. (a) Retrieved and (b) radiosonde mean equivalent potential temperature profiles as a function of MJO phase: suppressed phase (dashed black), phases 2 and 3 (solid blue), phases 4 and 5 (dashed blue), phases 6 and 7 (red), and phases 8 and 1 (green). At Gan Island, phases 1-3 are more convective and 4-8 are more suppressed. 

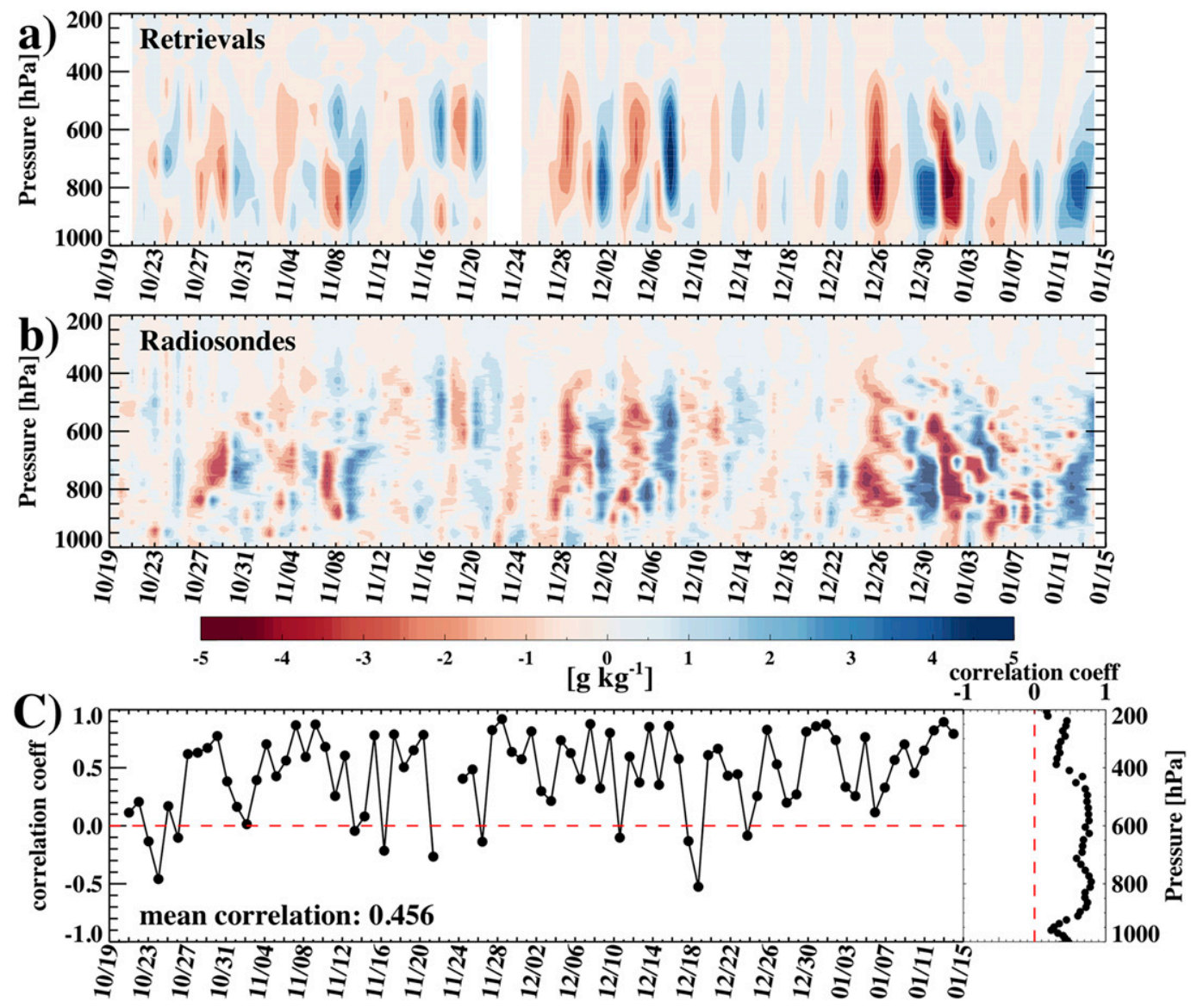

FIG. 12. Time series of vertically resolved daily mean difference of $q$ from (a) radiometer-retrieved profiles and (b) radiosonde profiles, with drying shown in red and moistening in blue. Also shown are (c) vertical (to the left) and temporal (to the right) correlation coefficients between the radiosonde and profile retrievals.

A radiosonde-only composite that is based on 8 of the 11 events shown in Fig. 4 of Zuluaga and Houze (2013) is similar to their larger composite (Fig. 13, bottom panel; two events precede the radiometer time series, and the event on 18 November is extreme and dominates the composite when included). A 3-h running mean is applied to the radiometer moisture profile retrievals, shown as anomalies from the mean profile (Fig. 13, top panel). The corresponding water vapor paths from both the radiosondes and retrievals are also indicated, as is the number of converged retrieval samples (above the top panel in Fig. 13).

The qualitative changes in the moisture field are captured to some extent by the humidity retrievals, although the time scale is not consistent. Not unexpected, the composite of the profile retrievals is no longer realistic close to the time of maximum rainfall, when fewer converged retrievals are available. This lack of converged samples also affects the composite of the water vapor paths calculated from the profile retrievals. The differences can be interpreted as a vertical offset in the retrieved humidity anomalies, and in particular the boundary layer behavior is not correct within the retrievals. While fewer retrievals are realistic close to the time of strong convective events, the resolution of a vertical structure suggests the potential for synergism with an additional measurement such as from a water vapor lidar (Weckwerth et al. 2016), which, while quickly attenuated by cloud, can still resolve the lower-level humidity vertical structure well and thereby help constrain the entire profile.

\section{d. Diurnal-cycle evolution during a suppressed MJO phase}

A last examination is of a diurnal cycle during specific MJO onset conditions. On two occasions, 7-13 October and 11-16 November, a large-scale drying anomaly in the morning is followed by a comparable evening moistening anomaly after clouds begin to develop (Fig. 16 in Ruppert and Johnson 2015). These time periods are not overly suppressed, with water vapor paths of approximately $5.5 \mathrm{~cm}$, but rather correspond to transition time periods when the vertical advection of moisture can be constructively interacting with horizontal moisture advection. 

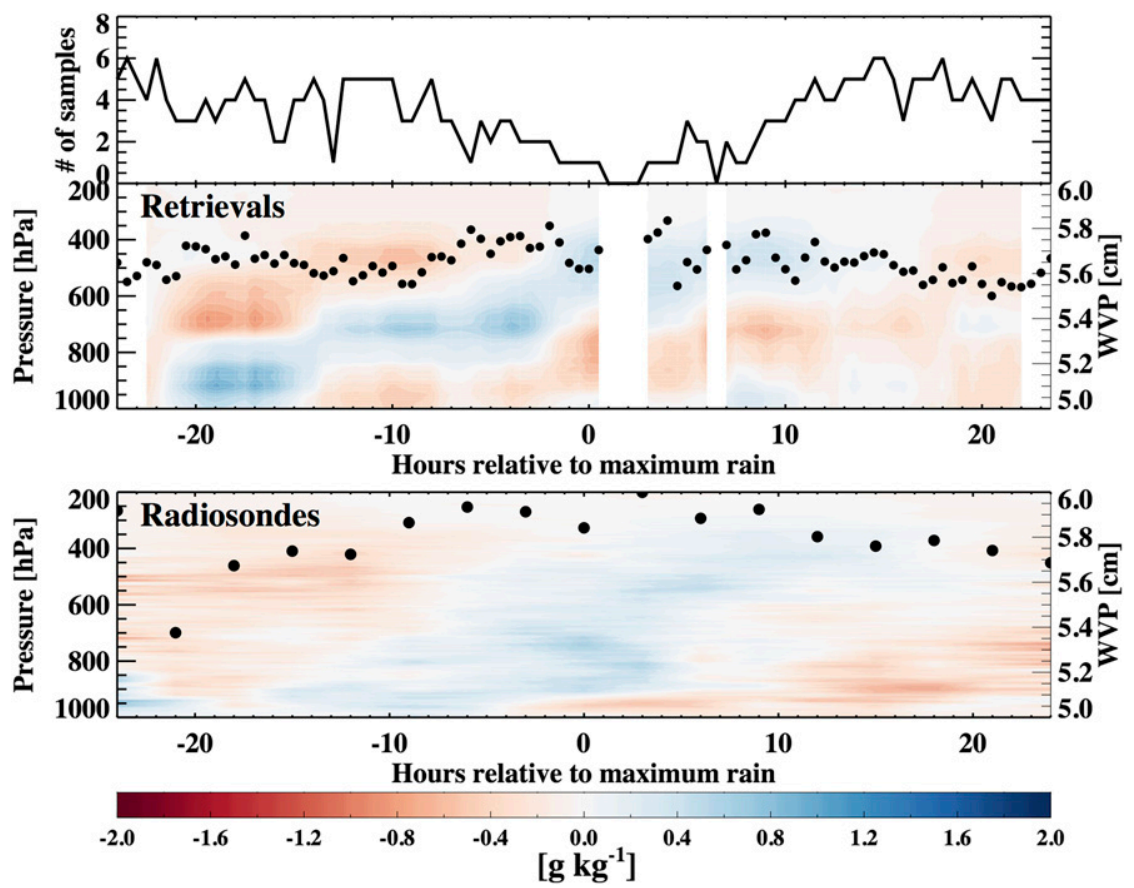

FIG. 13. (top) Composite time-height section of retrieved moisture deviations from the mean profile and WVPs of the eight selected rainiest (maximum in rain accumulation) events during DYNAMO according to Zuluaga and Houze (2013, their Table 3), from -22.5 to $+22 \mathrm{~h}$ relative to the maxima in rainfall accumulation. Moist deviations are in blue, and dry deviations are in red. The column-integrated WVP is indicated by the black dots and is calculated from the retrieved profiles. Profiles are retrieved at 30-min resolution, and a 3 -h running mean is applied to the retrievals. The number of converged samples at each time step is shown above the panel. (bottom) The corresponding radiosonde-derived moisture profile and WVP (black dots).

A composite is constructed for the $11-16$ November time period using the profile retrievals and the radiosondes (Fig. 14). The radiosonde water vapor mixing ratios capture the same diurnal features as the gridded analysis applied within Ruppert and Johnson (2015), with even slightly larger magnitudes reaching $0.5 \mathrm{~g} \mathrm{~kg}^{-1}$. The radiosondederived water vapor paths vary diurnally by approximately $0.2 \mathrm{~cm}$, a variation that is well captured by the retrievals. Portions of the moisture profile diurnal variability are also captured, such as the moistening after 1700 local time, particularly at altitudes above $900 \mathrm{hPa}$, if exaggerated in magnitude. A boundary layer to midtroposphere drying starting at midnight and capping a near-surface moistening beginning after sunrise is evident in the retrieval composite as well. A weaker moistening above $500 \mathrm{hPa}$, presumably reflecting large-scale horizontal advection, is also captured by the retrievals.

The most distinct discrepancy between the two composites is an exaggerated vertical bimodality within the retrieval composite, with maximum moisture anomalies reaching $1 \mathrm{~g} \mathrm{~kg}^{-1}$. This is most obvious in the time period centered around local noon, when a more moist boundary layer is capped by a drier midtroposphere. The vertical structure is arguably also evident in the radiosonde composite, but the retrieval composite exaggerates the structure by an order of magnitude. The effect of a systematic afternoon warming reaching $0.4 \mathrm{~K}$ in the midtroposphere (Figs. 1 and 4b of Ruppert 2016) may be aliased into the humidity retrievals shown, but the results here also point to the underconstrained nature of the retrieval. In more-suppressed conditions in which obstruction by cloud is less of a problem, the additional information from an infrared spectrometer may help to improve the characterization of the diurnal response (Turner and Löhnert 2014).

\section{Conclusions}

Optimally estimated moisture profiles retrieved from the radiances of a ground-based microwave radiometer in a tropical environment are evaluated for their ability to provide insight into tropical humidity variability at a range of time scales. The retrieved humidity profiles are constrained by the previously retrieved integrated water vapor paths, which match those from the radiosondes well except in highly convective conditions. The 

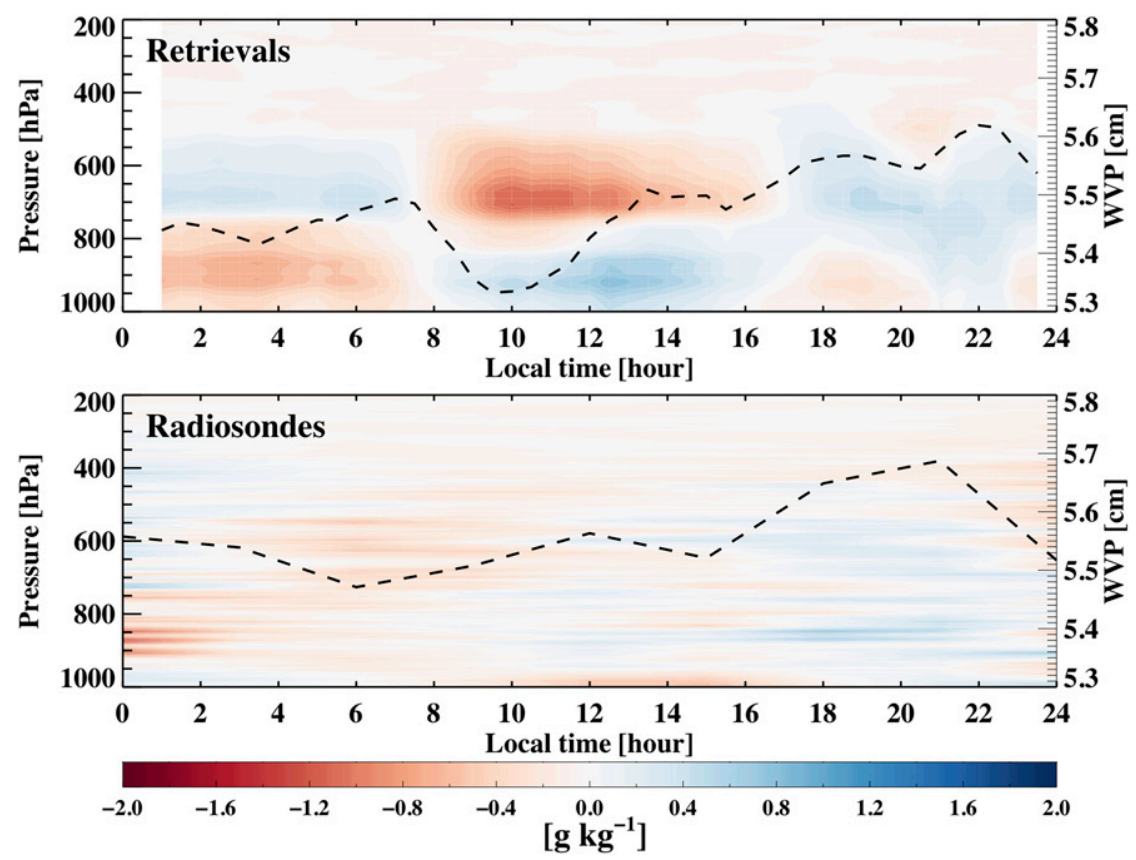

FIG. 14. Diurnal-cycle composite of the (top) retrieved and (bottom) radiosonde profile of $q$ from 11 to 16 Nov. Moistening is indicated in blue, and drying is shown in red. Columnintegrated WVPs are shown as black dashed curves.

moisture retrievals possess about 2.2 degrees of freedom, allowing the atmosphere to be treated as two independent layers. The mean bias in the water vapor mixing ratio profile is approximately $1 \mathrm{~g} \mathrm{~kg}^{-1}$ relative to the radiosondes, with the sign of the bias changing with height. The mean vertical structure of the bias is removed in the applications.

At time scales of at least 1 day, for which the amplitude of the humidity fluctuations in nature exceeds the uncertainty (Fig. 7), the moisture variability is captured well in two independent layers (selected to be 1000-700 and $700-400 \mathrm{hPa}$; Figs. 10 and 12). These are adequate for capturing large-scale moisture changes that are often highly vertically coherent. The layer-mean values are also well represented during time periods when the changing moisture vertical distribution is not coherent. At these time scales, the autonomous radiometers can usefully augment radiosonde networks (e.g., Johnson et al. 2015), which are often sparse and are expensive, and add vertical resolution to the satellite column measures of moisture (e.g., Hannah et al. 2016). The ability to explicitly resolve two layers holds the potential to evaluate select convectionhumidity relationships at similar scales (Muller et al. 2009; Ahmed and Schumacher 2015). Careful crossinstrument calibration would be required to ensure a consistent response by the radiometers to the environmental humidity.
At short time scales, within suppressed conditions that are making the transition to more-convective conditions, the diurnal cycle in the retrieved humidity profile characterized by the microwave radiometer is qualitatively reasonable (Fig. 13), although an exaggerated vertical bimodality indicates the underconstrained nature of the retrieval. In more-convective conditions, the retrievals do not match the radiosonde profiles within most of the day prior to/after the main convective event, despite the radiometer's imperviousness to clouds. At these shorter time scales, synergism with other instruments that are able to resolve the lower-level moisture in particular, such as lidar and infrared spectrometers, may be able to improve on the realism of the vertically resolved humidity retrievals (e.g., Turner and Löhnert 2014; Barrera-Verdejo et al. 2016). Although these findings are not necessarily new, this study underscores best practices for incorporating microwave radiometer measurements into studies of tropical environments, for which the interactions between tropical humidity and convection remain an important research frontier (e.g., Holloway et al. 2017), with an emphasis on the resolution of two vertical layers.

Acknowledgments. This work was supported by National Science Foundation Grant AGS-132189 "Connecting small-scale humidity-variability to dynamical processes governing MJO transitions." We acknowledge 

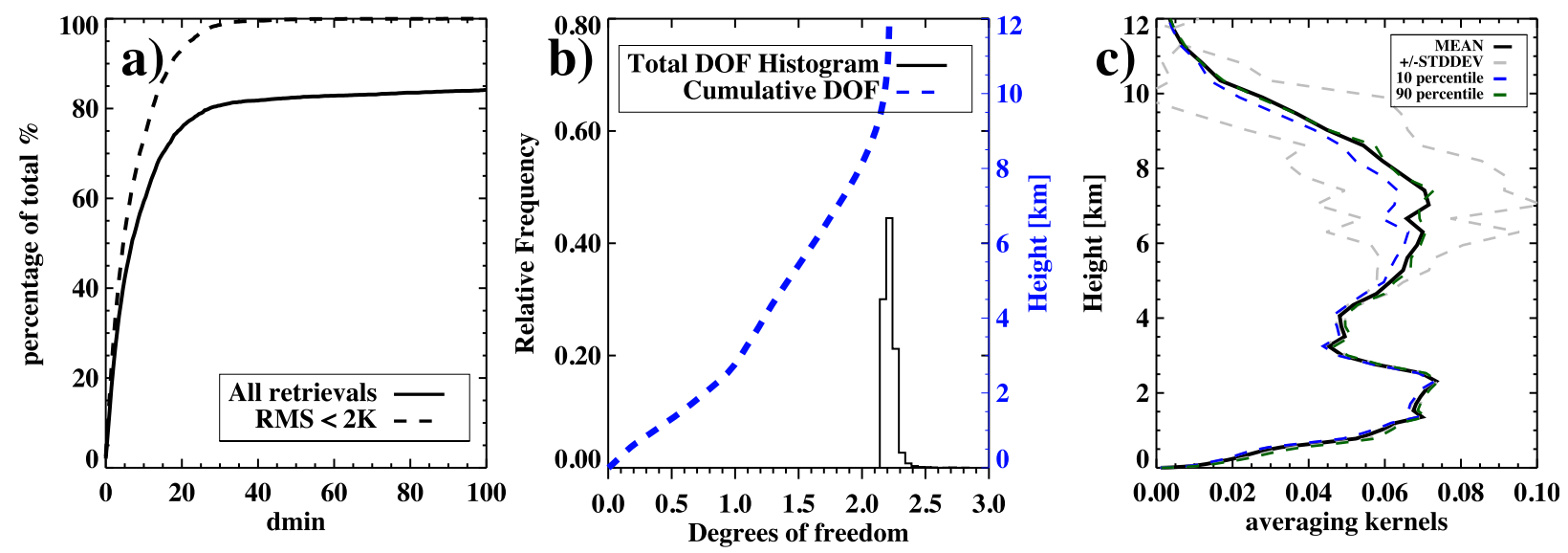

FIG. A1. (a) The accumulative probability distribution diagram of dmin. Values are indicated for retrievals before and after the quality controls (solid and dashed lines, respectively). (b) Histogram of total (solid) and cumulative (dashed) degrees of freedom as function of height. (c) Vertical distribution of the averaging kernels, shown for the mean (black solid), \pm 1 standard deviation (gray dashed), and the 10th and 90th percentiles (blue and green dashed lines, respectively) of all profile retrievals that pass quality controls (the vertical sum of the averaging kernels is the DFS).

use of data from the ARM Climate Research Facility that are available at the ARM Data Archive (https:// www.arm.gov/data). The authors thank Dr. Arun Chandra and four anonymous reviewers for their constructive comments.

\section{APPENDIX}

\section{Optimal Estimation Implementation and Testing}

The optimal solution of an ill-posed inverse problem can be found by iterating the following formulation, assuming a linear solution applies (Rodgers 2000):

$$
\begin{aligned}
\mathbf{X}_{i+1}= & \mathbf{X}_{i}+\left(\mathbf{K}_{i}^{\mathrm{T}} \mathbf{S}_{e}^{-1} \mathbf{K}_{i}+\mathbf{S}_{a}^{-1}\right)^{-1}\left[\mathbf{K}_{i}^{\mathrm{T}} \mathbf{S}_{e}^{-1}\left(\mathbf{y}-\mathbf{y}_{i}\right)\right. \\
& \left.+\mathbf{S}_{a}^{-1}\left(\mathbf{X}_{a}-\mathbf{X}_{i}\right)\right] \text { and } \\
\mathbf{K}_{i}= & \frac{\partial F\left(\mathbf{X}_{i}\right)}{\partial \mathbf{X}_{i}}
\end{aligned}
$$

where $\mathbf{X}_{i}$ is the atmospheric water vapor mixing ratio $q(z)$ profile being retrieved at iteration $i, \mathbf{X}_{a}$ represents the a priori information of the campaign-mean radiosonde $q(z)$ profile, $\mathbf{S}_{a}$ represents the a priori covariance matrix, and $\mathbf{S}_{e}$ represents the measurement error covariance matrix. The Jacobian $\mathbf{K}_{i}$ is calculated at each iteration by perturbing the $q(z)$ vector level by level as shown in Eq. (A2), representing the sensitivity of the forward model to changes in the humidity at different levels. Values of $\mathbf{y}$ are the brightness temperatures measured by the microwave radiometer, and $\mathbf{y}_{i}$ [or $F\left(\mathbf{X}_{i}\right)$ ] are the forward-calculated brightness temperatures from state vector $\mathbf{X}_{i}$ from the radiative transfer model.
The superscripts -1 and $\mathrm{T}$ denote matrix inverse and transpose, respectively.

The iteration in Eq. (A1) should provide an optimal solution when the quadratic cost function between $\mathbf{X}_{a}$ and $\mathbf{X}_{i}$ is minimized or, in other words, when the difference between $\mathbf{X}_{i+1}$ and $\mathbf{X}_{i}$ approaches zero. The quadratic cost function between $\mathbf{X}_{i+1}$ and $\mathbf{X}_{i}$, or

$$
d=\left(\mathbf{X}_{i+1}-\mathbf{X}_{i}\right)^{\mathrm{T}} \mathbf{S}_{\mathrm{op}}\left(\mathbf{X}_{i+1}-\mathbf{X}_{i}\right),
$$

where $\mathbf{S}_{\mathrm{op}}$ is the covariance matrix of the optimal solution, can be written as

$$
\mathbf{S}_{\mathrm{op}}=\left(\mathbf{K}_{i}^{\mathrm{T}} \mathbf{S}_{e}^{-1} \mathbf{K}_{i}+\mathbf{S}_{a}^{-1}\right)^{-1} .
$$

We apply a more relaxed convergence criterion than that recommended in Rodgers (2000), thereby gaining a higher convergence rate without overly compromising the quality of the retrievals. The quadratic cost function $d$ was found to decrease with increasing iteration step until reaching a minimum, after which the quadratic cost function increased again. The minimum $d$ is saved as dmin, indicating the best performance (optimal estimation) of the iterations. As shown in Fig. A1a (solid curve), the convergence saturates at a dmin of approximately 50, with little gain in relaxing dmin criteria thereafter, providing a convergence rate of approximately $82 \%$. A $100 \%$ convergence rate was reached after all of the quality controls were imposed (Fig. A1a, dashed curve). The off-diagonal elements of $\mathbf{S}_{\text {op }}$ represent the correlation of errors between different levels. The convergence rate increases slightly when the humidity profile is scaled by the retrieved WVP between 
iterations. Retrievals with large biases are further excluded by only keeping the retrievals with root-meansquares of the fit of less than or equal to $2 \mathrm{~K}$ and an LWP of less than $500 \mathrm{~g} \mathrm{~m}^{-2}$, to minimize the possibility of precipitation contamination.

Vertical information content is given by the averaging kernel matrix $\mathbf{A}$, which can be written as

$$
\mathbf{A}=\mathbf{S}_{\mathrm{op}}\left(\mathbf{K}_{\mathrm{op}}^{\mathrm{T}} \mathbf{S}_{e}^{-1} \mathbf{K}_{\mathrm{op}}\right),
$$

where $\mathbf{K}_{\mathrm{op}}$ is the Jacobian calculated at the iteration when optimal estimation (convergence) has been reached. The rows of $\mathbf{A}$ indicate the vertical resolution (Rodgers 2000), whereas the trace of $\mathbf{A}$ represents the vertical degrees of freedom, meaning the number of independent vertical levels that can be retrieved from the observations. Figure A1b shows that the vertical distribution of the degrees of freedom for signal (DFS) is centered at approximately 2.2 . The cumulative DFS is given by accumulating values of each element on the diagonal of $\mathbf{A}$ and reaches $\sim 2.2$ at $10 \mathrm{~km}$. Furthermore, a vertical frequency distribution of DFS indicates two modes, one centered at $\sim 2 \mathrm{~km}$ and another centered at $\sim 7 \mathrm{~km}$ (Fig. A1c). This also indicates that the optimal estimation approach is more prone to vary the humidity within $1-3 \mathrm{~km}$ and within $5-9 \mathrm{~km}$. Of interest here is that this panel suggests that almost all of the variability in DFS is contained in the upper troposphere, above $5 \mathrm{~km}$.

The measurement error covariance matrix $\mathbf{S}_{e}$ only contains the nonzero elements on the diagonal components, whereas the off-diagonal elements are set to zero since we assume that measurement uncertainties at different frequencies are independent of each other. This assumption has been borne out through an independent assessment of a similar radiometer at the DOE Southern Great Plains site (a covariance of $0.002 \mathrm{~K}^{2}$ between the 23- and $30-\mathrm{GHz}$ channels). The diagonal elements assume that each channel's noise level is $0.3 \mathrm{~K}$, consistent with that of the similarly manufactured ARM radiometer.

Additional testing of the algorithm's setup included manipulation of the vertical grid spacing, which found minimal resulting differences in the retrievals. A semiexponential vertical grid was chosen after taking both performance and computing efficiency into account. The choice of the a priori information is another challenge. The idea to include all sky conditions as the a priori information aimed to help with the retrievals under moist conditions, whereas the idea to only use the clear-sky radiosondes for the a priori information was to exclude heavily precipitating samples. It is interesting that the testing of both conditions revealed no obvious differences in the performance of the retrievals. Another experiment added surface specific humidity measurements collected from a surface meteorological station at the S-PolKa site to the observation vector as a potential constraint on the boundary layer moisture. Only the first level of the retrieval is impacted by the addition of this new information, with no improvement to the boundary layer retrievals. Moreover, the surface humidity measurements did not compare well to the lowest levels of the radiosondes, which were launched at a different location. Thus, the surface specific humidity is not included in the retrieval.

\section{REFERENCES}

Ahmed, F., and C. Schumacher, 2015: Convective and stratiform components of the precipitation-moisture relationship. Geophys. Res. Lett., 42, 10 453-10 462, https://doi.org/10.1002/ 2015 GL066957.

Barrera-Verdejo, M., S. Crewell, U. Löhnert, E. Orlandi, and P. Di Girolamo, 2016: Ground-based lidar and microwave radiometry synergy for high vertical resolution absolute humidity profiling. Atmos. Meas. Tech., 9, 4013-4028, https://doi.org/ 10.5194/amt-9-4013-2016.

Benedict, J. J., and D. A. Randall, 2007: Observed characteristics of the MJO relative to maximum rainfall. J. Atmos. Sci., 64, 2332-2354, https://doi.org/10.1175/JAS3968.1.

Bladé, I., and D. L. Hartmann, 1993: Tropical intraseasonal oscillations in a simple nonlinear model. J. Atmos. Sci., 50, 2922-2939, https://doi.org/10.1175/1520-0469(1993)050<2922: TIOIAS $>2.0$.CO;2.

Blumberg, W. G., D. D. Turner, U. Löhnert, and S. Castleberry, 2015: Ground-based temperature and humidity profiling using spectral infrared and microwave observations. Part II: Actual retrieval performance in clear-sky and cloudy conditions. J. Appl. Meteor. Climatol., 54, 2305-2319, https://doi.org/ 10.1175/JAMC-D-15-0005.1.

Cadeddu, M. P., J. C. Liljegren, and D. D. Turner, 2013: The Atmospheric Radiation Measurement (ARM) program network of microwave radiometers: Instrumentation, data, and retrievals. Atmos. Meas. Tech., 6, 2359-2372, https://doi.org/ 10.5194/amt-6-2359-2013.

_ R. Marchand, E. Orlandi, D. D. Turner, and M. Mech, 2017: Microwave passive ground-based retrievals of cloud and rain liquid water path in drizzling clouds: Challenges and possibilities. IEEE Trans. Geosci. Remote Sens., 55, 6468-6481, https://doi.org/10.1109/TGRS.2017.2728699.

Chikira, M., 2014: Eastward-propagating intraseasonal oscillation represented by Chikira-Sugiyama cumulus parameterization. Part II: Understanding moisture variation under weak temperature gradient balance. J. Atmos. Sci., 71, 615-639, https:// doi.org/10.1175/JAS-D-13-038.1.

Ciesielski, P. E., and Coauthors, 2014: Quality-controlled upper-air sounding dataset for DYNAMO/CINDY/AMIE: Development and corrections. J. Atmos. Oceanic Technol., 31, 741-764, https://doi.org/10.1175/JTECH-D-13-00165.1.

- R. H. Johnson, X. Jiang, Y. Zhang, and S. Xie, 2017: Relationships between radiation, clouds, and convection during DYNAMO. J. Geophys. Res. Atmos., 122, 2529-2548, https:// doi.org/10.1002/2016JD025965.

Clough, S. A., M. W. Shephard, E. J. Mlawer, J. S. Delamere, M. J. Iacono, K. Cady-Pereira, S. Boukabara, and P. D. Brown, 
2005: Atmospheric radiative transfer modeling: A summary of the AER codes. J. Quant. Spectrosc. Radiat. Transfer, 91, 233-244, https://doi.org/10.1016/j.jqsrt.2004.05.058.

Gottschalck, J., P. E. Roundy, C. J. Schreck III, A. Vintzileos, and C. Zhang, 2013: Large-scale atmospheric and oceanic conditions during the 2011-12 DYNAMO field campaign. Mon. Wea. Rev., 141, 4173-4196, https://doi.org/10.1175/MWR-D-13-00022.1.

Hannah, W. M., B. E. Mapes, and G. S. Elsaesser, 2016: A Lagrangian view of moisture dynamics during DYNAMO. J. Atmos. Sci., 73, 1967-1985, https://doi.org/10.1175/JAS-D15-0243.1.

Hewison, T. J., 2007: 1D-VAR retrieval of temperature and humidity profiles from a ground-based microwave radiometer. IEEE Trans. Geosci. Remote Sens., 45, 2163-2168, https:// doi.org/10.1109/TGRS.2007.898091.

Hohenegger, C., and B. Stevens, 2013: Preconditioning deep convection with cumulus congestus. J. Atmos. Sci., 70, 448-464, https://doi.org/10.1175/JAS-D-12-089.1.

Hoke, M. L., S. A. Clough, W. J. Lafferty, and B. W. Olson, 1989: Line coupling in oxygen and carbon dioxide. IRS 88: Current Problems in Atmospheric Radiation, Deepak, 368-371.

Holloway, C. E., and J. D. Neelin, 2009: Moisture vertical structure, column water vapor, and tropical deep convection. J. Atmos. Sci., 66, 1665-1683, https://doi.org/10.1175/2008JAS2806.1.

_ A. A. Wing, S. Bony, C. Muller, H. Masunaga, T. S. L'Ecuyer, D. D. Turner, and P. Zuidema, 2017: Observing convective aggregation. Surv. Geophys., 38, 1199-1236, https://doi.org/ 10.1007/s10712-017-9419-1.

Humliček, 1982Humliček, J., 1982: Optimized computation of the Voigt and complex probability functions. J. Quant. Spectrosc. Radiat. Transfer, 27, 437-444, https://doi.org/10.1016/00224073(82)90078-4.

Johnson, R. H., P. E. Ciesielski, J. H. J. Ruppert, and M. Katsumata, 2015: Sounding-based thermodynamic budgets for DYNAMO. J. Atmos. Sci., 72, 598-622, https://doi.org/ 10.1175/JAS-D-14-0202.1.

Kuo, Y., K. Schiro, and J. Neelin, 2018: Convective transition statistics over tropical oceans for climate model diagnostics: Observational baseline. J. Atmos. Sci., 75, 1553-1570, https:// doi.org/10.1175/JAS-D-17-0287.1.

Löhnert, U., and O. Maier, 2012: Operational profiling of temperature using ground-based microwave radiometry at Payerne: Prospects and challenges. Atmos. Meas. Tech., 5, 1121-1134, https://doi.org/10.5194/amt-5-1121-2012.

_, S. Crewell, and C. Simmer, 2004: An integrated approach toward retrieving physically consistent profiles of temperature, humidity, and cloud liquid water. J. Appl. Meteor., 43, 1295-1307, https://doi.org/10.1175/1520-0450(2004)043<1295: AIATRP $>2.0 . \mathrm{CO} ; 2$.

— E. Ean Meijgaard, H. K. Baltink, S. Groß, and R. Boers, 2007: Accuracy assessment of an integrated profiling technique for operationally deriving profiles of temperature, humidity, and cloud liquid water. J. Geophys. Res., 112, D04205, https:// doi.org/10.1029/2006JD007379.

, D. D. Turner, and S. Crewell, 2009: Ground-based temperature and humidity profiling using spectral infrared and microwave observations. Part I: Simulated retrieval performance in clearsky conditions. J. Appl. Meteor. Climatol., 48, 1017-1032, https:// doi.org/10.1175/2008JAMC2060.1.

Long, C., and Coauthors, 2011: ARM MJO investigation experiment on Gan Island (AMIE-Gan) science plan. DOE/ARM Tech. Rep. DOE/SC-ARM-11-005, 63 pp., https://www.arm.gov/ publications/programdocs/doe-sc-arm-11-005.pdf.
Mapes, B., S. Tulich, J. Lin, and P. Zuidema, 2006: The mesoscale convection life cycle: Building block or prototype for largescale tropical waves. Dyn. Atmos. Oceans, 42, 3-29, https:// doi.org/10.1016/j.dynatmoce.2006.03.003.

, A. S. Chandra, Z. Kuang, and P. Zuidema, 2017: Importance profiles for water vapor. Surv. Geophys., 38, 1355-1369, https://doi.org/10.1007/s10712-017-9427-1.

Miller, M. A., K. Nitschke, T. P. Ackerman, W. R. Ferrell, N. Hickmon, and M. Ivey, 2016: The ARM Mobile Facilities. The Atmospheric Radiation Measurement (ARM) Program: The First 20 Years, Meteor. Monogr., No. 57, Amer. Meteor. Soc., https://doi.org/10.1175/AMSMONOGRAPHS-D-15-0051.1.

Muller, C. J., L. E. Back, P. A. O'Gorman, and K. A. Emanuel, 2009: A model for the relationship between tropical precipitation and column water vapor. Geophys. Res. Lett., 36, L16804, https://doi.org/10.1029/2009GL039667.

Payne, V. H., J. S. Delamere, K. E. Cady-Pereira, R. R. Gamache, J. L. Moncet, E. J. Mlawer, and S. A. Clough, 2008: Airbroadened half-widths of the $22-$ and $183-\mathrm{GHz}$ water-vapor lines. IEEE Trans. Geosci. Remote Sens., 46, 3601-3617, https://doi.org/10.1109/TGRS.2008.2002435.

Powell, S. W., and R. A. J. Houze, 2013: The cloud population and onset of the Madden-Julian Oscillation over the Indian Ocean during DYNAMO-AMIE. J. Geophys. Res. Atmos., 118, 11979-11 995, https://doi.org/10.1002/2013JD020421.

Raju, C. S., R. Renju, T. Antony, N. Mathew, and K. K. Moorthy, 2013: Microwave radiometric observation of a waterspout over coastal Arabian Sea. IEEE Geosci. Remote Sens. Lett., 10, 1075-1079, https://doi.org/10.1109/LGRS.2012.2229960.

Rodgers, C. D., 2000: Inverse Methods for Atmospheric Sounding. World Scientific, $256 \mathrm{pp}$.

Ruppert, J. H., Jr., 2016: Diurnal timescale feedbacks in the tropical cumulus regime. J. Adv. Model. Earth Syst., 8, 1483-1500, https://doi.org/10.1002/2016MS000713.

, and R. H. Johnson, 2015: Diurnally modulated cumulus moistening in the preonset stage of the Madden-Julian Oscillation during DYNAMO. J. Atmos. Sci., 72, 1622-1647, https://doi.org/10.1175/JAS-D-14-0218.1.

Sahoo, S., X. Bosch-lluis, S. C. Reising, S. Member, S. M. Ellis, J. Vivekanandan, S. Member, and P. Zuidema, 2015: Retrieval of slant water vapor path and slant liquid water from microwave radiometer measurements during the DYNAMO Experiment. IEEE J. Sel. Top. Appl. Earth Obs. Remote Sens., 8, 4315-4324, https://doi.org/10.1109/ JSTARS.2015.2445785.

Schiro, K. A., and J. D. Neelin, 2018: Tropical continental downdraft characteristics: mesoscale systems versus unorganized convection. Atmos. Chem. Phys., 18, 1997-2010, https:// doi.org/10.5194/acp-18-1997-2018.

Sherwood, S. C., 1999: Convective precursors and predictability in the tropical western Pacific. Mon. Wea. Rev., 127, 2977-2991, https:// doi.org/10.1175/1520-0493(1999)127<2977:CPAPIT>2.0.CO;2.

Sobel, A. H., J. Nilsson, and L. M. Polvani, 2001: The weak temperature gradient approximation and balanced tropical moisture waves. J. Atmos. Sci., 58, 3650-3665, https://doi.org/ 10.1175/1520-0469(2001)058<3650:TWTGAA > 2.0.CO;2.

Tompkins, A. M., and A. G. Semie, 2017: Organization of tropical convection in low vertical wind shears: Role of updraft entrainment. J. Adv. Model. Earth Syst., 9, 1046-1068, https:// doi.org/10.1002/2016MS000802.

Turner, D. D., and U. Löhnert, 2014: Information content and uncertainties in thermodynamic profiles and liquid cloud properties retrieved from the ground-based Atmospheric 
Emitted Radiance Interferometer (AERI). J. Appl. Meteor. Climatol., 53, 752-771, https://doi.org/10.1175/JAMC-D-13-0126.1.

, S. A. Clough, J. C. Liljegren, E. E. Clothiaux, K. E. CadyPereira, and K. L. Gaustad, 2007: Retrieving liquid water path and precipitable water vapor from the Atmospheric Radiation Measurement (ARM) microwave radiometers. IEEE Trans. Geosci. Remote Sens., 45, 3680-3689, https://doi.org/10.1109/ TGRS.2007.903703.

—, M. P. Cadeddu, U. Löhnert, S. Crewell, and A. M. Vogelmann, 2009: Modifications to the water vapor continuum in the microwave suggested by ground-based 150-ghz observations. IEEE Trans. Geosci. Remote Sens., 47, 3326-3337, https:// doi.org/10.1109/TGRS.2009.2022262.

Wang, J., L. Zhang, A. Dai, F. Immler, M. Sommer, and H. Vömel, 2013: Radiation dry bias correction of Vaisala RS92 humidity data and its impacts on historical radiosonde data. J. Atmos. Oceanic Technol., 30, 197-214, https://doi.org/10.1175/JTECH-D12-00113.1.

Weckwerth, T. M., K. J. Weber, D. D. Turner, and S. M. Spuler, 2016: Validation of a water vapor micropulse differential absorption lidar (DIAL). J. Atmos. Oceanic Technol., 33, 2353-2372, https://doi.org/10.1175/JTECH-D-16-0119.1.

Wheeler, M. C., and H. H. Hendon, 2004: An all-season real-time multivariate MJO index: Development of an index for monitoring and prediction. Mon. Wea. Rev., 132, 1917-1932, https://doi.org/ 10.1175/1520-0493(2004)132<1917:AARMMI>2.0.CO;2.

Xu, W., and S. A. Rutledge, 2016: Time scales of shallow-to-deep convective transition associated with the onset of MaddenJulian Oscillations. Geophys. Res. Lett., 43, 2880-2888, https:// doi.org/10.1002/2016GL068269.

Yoneyama, K., C. Zhang, and C. N. Long, 2013: Tracking pulses of the Madden-Julian oscillation. Bull. Amer. Meteor. Soc., 94, 1871-1891, https://doi.org/10.1175/BAMS-D-12-00157.1.

Zhang, C., 2005: Madden-Julian Oscillation. Rev. Geophys., 43, RG2003, https://doi.org/10.1029/2004RG000158.

Zuidema, P., E. Westwater, C. Fairall, and D. Hazen, 2005: Ship-based liquid water path estimates in marine stratocumulus. J. Geophys. Res., 110, D20206, https://doi.org/10.1029/2005JD005833.

—, G. Torri, C. Muller, and A. Chandra, 2017: A survey of precipitation-induced atmospheric cold pools over oceans and their interactions with the larger-scale environment. Surv. Geophys., 38, 1283-1305, https://doi.org/10.1007/s10712-0179447-x.

Zuluaga, M. D., and R. A. J. Houze, 2013: Evolution of the population of precipitating convective systems over the equatorial Indian Ocean in active phases of the Madden-Julian oscillation. J. Atmos. Sci., 70, 2713-2725, https://doi.org/10.1175/ JAS-D-12-0311.1. 